\title{
Aerosol-cloud-precipitation effects over Germany as simulated by a convective-scale numerical weather prediction model
}

\author{
A. Seifert ${ }^{1}$, C. Köhler ${ }^{1,2}$, and K. D. Beheng ${ }^{3}$ \\ ${ }^{1}$ Deutscher Wetterdienst, Offenbach, Germany \\ ${ }^{2}$ Deutsches Zentrum für Luft- und Raumfahrt, Institut für Physik der Atmosphäre,Oberpfaffenhofen, Germany \\ ${ }^{3}$ Karlsruher Institut für Technologie, Institut für Meteorologie und Klimaforschung, Karlsruhe, Germany \\ Correspondence to: A. Seifert (axel.seifert@dwd.de)
}

Received: 6 July 2011 - Published in Atmos. Chem. Phys. Discuss.: 18 July 2011

Revised: 5 December 2011 - Accepted: 8 January 2012 - Published: 16 January 2012

\begin{abstract}
Possible aerosol-cloud-precipitation effects over Germany are investigated using the COSMO model in a convection-permitting configuration close to the operational COSMO-DE. Aerosol effects on clouds and precipitation are modeled by using an advanced two-moment microphysical parameterization taking into account aerosol assumptions for cloud condensation nuclei (CCN) as well as ice nuclei (IN). Simulations of three summer seasons have been performed with various aerosol assumptions, and are analysed regarding surface precipitation, cloud properties, and the indirect aerosol effect on near-surface temperature. We find that the $\mathrm{CCN}$ and IN assumptions have a strong effect on cloud properties, like condensate amounts of cloud water, snow and rain as well as on the glaciation of the clouds, but the effects on surface precipitation are - when averaged over space and time - small. This robustness can only be understood by the combined action of microphysical and dynamical processes. On one hand, this shows that clouds can be interpreted as a buffered system where significant changes to environmental parameters, like aerosols, have little effect on the resulting surface precipitation. On the other hand, this buffering is not active for the radiative effects of clouds, and the changes in cloud properties due to aerosol perturbations may have a significant effect on radiation and near-surface temperature.
\end{abstract}

\section{Introduction}

Understanding aerosol-cloud interactions is a major scientific challenge in current climate research. Interactions that involve microphysical effects and response as well as cloud dynamical feedbacks on multiple scales are especially hard to quantify (Solomon et al., 2007). Global climate and earth system models which suffer from very coarse horizontal resolution are unable to represent such feedbacks explicitly, especially those involving convective clouds, and need to rely on sensitivities emerging from the sub-grid parameterizations. Process studies as well as regional and convectivescale modeling are therefore necessary to clarify, evaluate and quantify those complex interactions.

The response of clouds to changes in the ambient aerosol, i.e. the indirect aerosol effect, is complex and may differ quantitatively and qualitatively depending on the cloud type or aerosol regime. One example of such complex behavior is the non-monotonic dependency of cloud fraction on aerosol concentration (Xue et al., 2008). In general, at least three different aerosol indirect effects can be distinguished (Lohmann and Feichter, 2005; Solomon et al., 2007):

1. Cloud lifetime effect: More CCN lead to smallerdroplets, decreasing precipitation efficiency and prolonging cloud lifetime (Albrecht, 1989).

2. Glaciation indirect effect: More IN lead to a more efficient glaciation of clouds and an increased precipitation efficiency (e.g. Lohmann, 2002; Lohmann and Hoose, 2009).

3. Aerosol cloud dynamics effect (thermodynamics effect): More CCN lead to smaller cloud droplets, which delays formation of raindrops and leads to more supercooled water freezing at higher altitudes. The additional latent heat release invigorates the clouds resulting in an 
increase in surface precipitation (Seifert and Beheng, 2006b; Khain et al., 2005; Koren et al., 2005; van den Heever et al., 2006; Fan et al., 2009).

To unravel aerosol indirect effects it is necessary to quantify those processes and feedbacks, and to understand which cloud regimes are affected in which manner by which chain of processes.

During the 1950s and '60s many aerosol-cloudprecipitation studies were done in the context of cloud seeding, i.e. the attempt to deliberately modify the microstructure of clouds with the aim of precipitation enhancement or hail suppression, topics which are still very controversial (Cotton, 1982, 2009; Garstang et al., 2005; Levin and Cotton, 2008). Today, in the broader context of climate change, the impact of unintentional anthropogenic changes of the atmospheric aerosol and the microstructure of clouds and precipitation are probably even more important (Borys et al., 2003; Rosenfeld and Givati, 2006; Alpert et al., 2008; Levin and Cotton, 2008; Ayers and Levin, 2009). Also in some recent suggestions for intentional anthropogenic climate changes, often called geo-engineering, aerosol-cloud effects play a major role (Cotton, 2009).

Aerosol-cloud-radiation feedbacks have, for example, been studied in detail by Grabowski et al. (1998) and Grabowski and Morrison (2011) using radiative-convective quasi-equilibrium simulations. Especially the latter study using a two-moment microphysics scheme shows that indirect aerosol effects on atmospheric processes and the radiation budget may be rather small, and that the dynamical feedbacks on the cloud- and meso-scale play an important role in buffering the system. In radiative-convective quasi-equilibrium the surface precipitation is strongly constrained by the surface heat flux and radiative cooling, therefore such simulations are not yet conclusive regarding aerosol-cloud-precipitation effects and feedbacks.

Here we explore aerosol-cloud-precipitation effects using methods and data from operational numerical weather prediction. This has the advantage that the modeling system we use is validated on a day-to-day basis, and we simply have to extend this system with a more sophisticated microphysical parameterization to be able to represent some important aspects of aerosol indirect effects. The disadvantage is that we ignore the variability and feedbacks of atmospheric chemistry and aerosol, i.e. by assuming low or high aerosol ( $\mathrm{CCN}$, IN) load in our experiments we just aim to capture the sensitivity of clouds and precipitation to a large-scale perturbation of the atmospheric aerosol. This exercise may be seen as an attempt at bracketing the aerosol effects by estimating an upper and lower bound, i.e. we do not strive to represent the full complexity of all chemistry-aerosol-cloud interactions, but to give a reasonable estimate for the sensitivity of the system taking into account the full meteorologically driven cloud regime variability. To make this feasible this study fo-

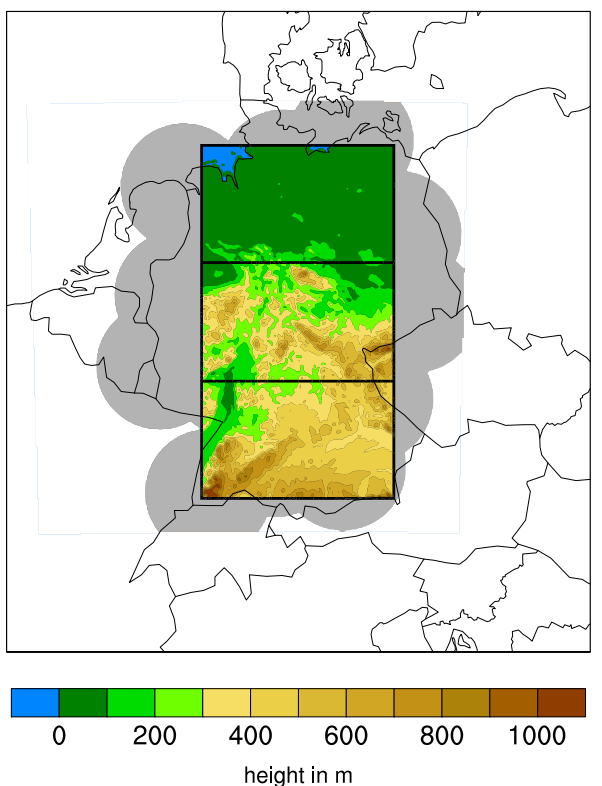

Fig. 1. COSMO-DE model domain, with insertions of coverage of the German radar composite (grey), and the three evaluation subdomains with the model orography.

cuses on summertime convective conditions in mid-latitudes, in particular in Germany.

The paper is organized as follows: In Sect. 2 we give an overview of the modeling systems and setup with details about the cloud microphysical parameterization used. Section 3 presents our results, followed by some conclusions in Sect. 4. Additional material is provided in an online supplement.

\section{Model description}

\subsection{COSMO-DE}

The non-hydrostatic compressible COSMO model ${ }^{1}$ is a limited-area numerical weather prediction (NWP) model developed by Deutscher Wetterdienst (DWD) and the COSMO consortium (Steppeler et al., 2003). COSMO-DE is an operational implementation of the COSMO model at DWD as a convective-scale shortest-range NWP model (Baldauf et al., 2011). With $421 \times 461$ grid points the COSMO-DE domain (Fig. 1) covers about $1200 \times 1300 \mathrm{~km}^{2}$ of central Europe including Germany, Switzerland, Austria, the Netherlands, Belgium, some parts of the neighboring countries and most of the Alps. It uses 50 model layers with a stretched vertical grid. The lowest layer is placed in $10 \mathrm{~m}$ above ground, and the model top is located at $22 \mathrm{~km}$ above mean sea level. The data assimilation system of COSMO-DE uses a nudging approach which includes the assimilation of high-resolution

\footnotetext{
${ }^{1}$ The model formerly known as Lokal Modell (LM).
} 
Table 1. Power law coefficients for the maximum diameter $D(x)=a x^{b}$ and the terminal fall velocity $v(x)=\alpha x^{\beta}$ of particles with mass $x$ as well as coefficients of the generalized Gamma distribution $f(x)=A x^{\nu} \exp \left(-B x^{\mu}\right)$ and maximum and minimum values for the mean particle mass $\bar{x}$ for the various hydrometeor types as used in the SB two-moment microphysics scheme. Below cloud base the raindrops follow the size-dependent Gamma shape parameterization of Seifert (2008).

\begin{tabular}{lllllllll}
\hline & $\begin{array}{l}a \\
\left(\mathrm{~m} \mathrm{~kg}^{-b}\right)\end{array}$ & $b$ & $\begin{array}{l}\alpha \\
\left(\mathrm{m} \mathrm{s}^{-1} \mathrm{~kg}^{-\beta}\right)\end{array}$ & & & & $\begin{array}{c}\bar{x}_{\min } \\
(\mathrm{kg})\end{array}$ & $\begin{array}{c}\bar{x}_{\max } \\
(\mathrm{kg})\end{array}$ \\
\hline cloud droplets & 0.124 & $1 / 3$ & $3.75 \times 10^{5}$ & $2 / 3$ & 1 & 1 & $4.2 \times 10^{-15}$ & $2.6 \times 10^{-10}$ \\
raindrops & 0.124 & $1 / 3$ & 114.0 & 0.234 & 0 & $1 / 3$ & $2.6 \times 10^{-10}$ & $3.0 \times 10^{-6}$ \\
cloud ice & 32.69 & 0.481 & 3447.0 & 0.630 & 0 & $1 / 3$ & $1.0 \times 10^{-12}$ & $1.0 \times 10^{-6}$ \\
snowflakes & 2.400 & 0.455 & 8.800 & 0.150 & 1 & $1 / 2$ & $1.0 \times 10^{-10}$ & $2.0 \times 10^{-5}$ \\
graupel & 0.142 & 0.314 & 33.00 & 0.187 & 1 & $1 / 3$ & $1.0 \times 10^{-9}$ & $5.0 \times 10^{-4}$ \\
hail & 0.134 & $1 / 3$ & 39.30 & 0.167 & 1 & $1 / 3$ & $2.6 \times 10^{-9}$ & $1.0 \times 10^{-4}$ \\
\hline
\end{tabular}

radar data by means of latent heat nudging (Stephan et al., 2008). Boundary conditions for COSMO-DE are provided by a $7 \mathrm{~km}$ grid-spacing COSMO model, called COSMO-EU, which itself is nested into a global model, the GME (Majewski et al., 2002). The COSMO-DE model configuration is based on an efficient Runge-Kutta solver following Wicker and Skamarock (2002), but with a vertically implicit solver which allows a time step of $\Delta t=25 \mathrm{~s}$. The one-moment cloud microphysics scheme used operationally predicts the mixing ratios of cloud water, rain water, cloud ice, snow and graupel and is combined with a simple mass-flux parameterization of non-precipitating shallow convection based on that part of the Tiedtke (1983) scheme. In such a model setup, which can be called convective-system resolving or convection-permitting, no parameterization of precipitating deep convection is used, i.e. all precipitation processes are explicitly represented by the grid-scale bulk microphysics scheme. For the cloud microphysics and precipitation processes the model uses only the grid box mean variables and no sub-grid variability is taken into account, e.g. condensation/evaporation of cloud droplets is parameterized by a saturation adjustment. For radiation and moist turbulence a subgrid cloud fraction is diagnosed using relative humidity or normalized saturation deficit. For more details we refer to Baldauf et al. (2011).

\subsection{Two-moment microphysics}

In this study we use the two-moment mixed-phase bulk microphysical parameterization of Seifert and Beheng (Seifert and Beheng, 2006a, SB hereafter) which predicts both the number densities and mass mixing ratios of the various hydrometeor types. This scheme has been especially designed to be able to represent aerosol effects on the microphysics of mixed-phase clouds. It has been successfully validated against a comprehensive spectral bin microphysics cloud model (Seifert et al., 2006). As most other advanced microphysics schemes, the SB scheme does simulate a strong response of cloud microphysics and precipitation to changes in the ambient aerosol for individual clouds (Seifert and Beheng, 2006b; Seifert et al., 2006). Hydrometeor size distributions are described by generalized Gamma distributions (parameters are given in Table 1). The raindrop size distribution is a Gamma distribution with a shape parameter depending on mean diameter (Seifert, 2005, 2008), and all warm rain processes as, e.g. autoconversion, accretion, etc., are parameterized as in Seifert (2008) based on Seifert and Beheng (2001).

The SB scheme has recently been extended to include a separate hail class considering wet growth processes and a spectral partitioning of freezing raindrops (Blahak, 2008). This hail-version of the SB scheme, which predicts the water mixing ratios $q_{x}$ and number densities $n_{x}$ of cloud droplets, rain, cloud ice, snow, graupel, and hail $(x \in\{c, r, i, s, g, h\})$ has successfully been applied to the simulation of a hail storm by Noppel et al. (2010). Important parameters of the SB scheme and the chosen values are summarized in Tables 1 and 2.

In the COSMO model the SB scheme is consistently coupled with the radiation scheme, i.e. effective radii of ice particles and cloud droplets are calculated in the microphysics scheme and passed to the radiation scheme. Optical properties are taken from Edwards et al. (2007) for ice particles and $\mathrm{Hu}$ and Stamnes (1993) for water clouds (Zubler et al., 2011).

\subsection{Aerosol assumptions and nucleation parameterizations}

In mixed-phase clouds aerosol particles can act as cloud condensation nuclei (CCN) or they may become ice nuclei (IN).

Activation of CCN from aerosol particles is computed using pre-calculated activation ratios stored in a look-up table (Segal and Khain, 2006). The activation ratios depend on the vertical velocity at cloud base and the properties of the aerosol (Noppel et al., 2010). All condensation nuclei (CN) are assumed to be soluble and follow a bi-modal size distribution. To calculate the look-up tables the number density 
Table 2. Some important parameters and coefficients as used in the current version of the SB two-moment microphysics scheme. Notations refers to SB, except for hail parameters which refer to Blahak (2008).

\begin{tabular}{llll}
\hline Notation & Description & Value & Unit \\
\hline$\alpha_{\circ}$ & space filling constant & 0.1 & \\
$\sigma_{i}$ & standard deviation of fallspeed for cloud ice & 0.0 & $\mathrm{~m} \mathrm{~s}^{-1}$ \\
$\sigma_{s}$ & standard deviation of fallspeed for snowflakes & 0.1 & $\mathrm{~m} \mathrm{~s}^{-1}$ \\
$\bar{D}_{c, 0}$ & constant in collisions efficiency for cloud droplets & $10 \times 10^{-6}$ & $\mathrm{~m}$ \\
$\bar{D}_{c, 1}$ & constant in collisions efficiency for cloud droplets & $40 \times 10^{-6}$ & $\mathrm{~m}$ \\
$\bar{D}_{g, 0}$ & constant in collisions efficiency for graupel & $100 \times 10^{-6}$ & $\mathrm{~m}$ \\
$\bar{D}_{h, 0}$ & constant in collisions efficiency for hail & $100 \times 10^{-6}$ & $\mathrm{~m}$ \\
$\bar{D}_{i, 0}$ & constant in collisions efficiency for cloud ice & $150 \times 10^{-6}$ & $\mathrm{~m}$ \\
$\bar{D}_{s, 0}$ & constant in collisions efficiency for snowflakes & $150 \times 10^{-6}$ & $\mathrm{~m}$ \\
$D_{\text {frz,ig }}$ & rain below this diameter freezes to cloud ice, above to graupel & $1.00 \times 10^{-3}$ & $\mathrm{~m}$ \\
$D_{\text {frz,gh }}$ & rain below this diameter freezes to graupel, above to hail & $1.25 \times 10^{-3}$ & $\mathrm{~m}$ \\
$\bar{D}_{\text {shed,g }}$ & graupel above this diameter starts shedding & $3.0 \times 10^{-3}$ & $\mathrm{~m}$ \\
$\bar{D}_{\text {shed, } h}$ & hail above this diameter starts shedding & $5.0 \times 10^{-3}$ & $\mathrm{~m}$ \\
$\bar{E}_{g, \text { max }}$ & maximum mean collision efficiency for graupel & 1.0 & \\
$\bar{E}_{h, \text { max }}$ & maximum mean collision efficiency for hail & 1.0 & \\
$\bar{E}_{i, \text { max }}$ & maximum mean collision efficiency for cloud ice & 0.8 & \\
$\bar{E}_{s, \text { max }}$ & maximum mean collision efficiency for snowflakes & 0.8 & \\
$k_{c c}$ & constant in cloud-cloud kernel & $9.44 \times 10^{9}$ & $\mathrm{~m}^{3} \mathrm{~kg}^{-2} \mathrm{~s}^{-1}$ \\
$k_{c r}$ & constant in cloud-rain kernel & 5.78 & $\mathrm{~m}^{3} \mathrm{~kg}^{-1} \mathrm{~s}^{-1}$ \\
$k_{r r}$ & constant in rain-rain kernel & 4.33 & $\mathrm{~m}^{3} \mathrm{~kg}^{-1} \mathrm{~s}^{-1}$ \\
\hline
\end{tabular}

$N_{\mathrm{CN}}$, mean radius of the larger aerosol mode $r_{2}$, and the logarithm of its geometric standard deviation $\log (\sigma)$ have to be prescribed. In contrast to the initial assumptions of the Segal and Khain (2006) scheme, CN are often not completely soluble, this fact is accounted for by a correction factor affecting the number of nucleated droplets. This empirical parameter $\epsilon$ is estimated to 0.9 for low and to 0.7 for very high $\mathrm{CN}$ number densities. For the vertical profile of $\mathrm{CN}$ we assume a constant number density, $N_{\mathrm{CN}}$, up to $2 \mathrm{~km}$ and an exponential decrease above that height.

In order to elucidate the effect of different aerosol and CCN concentrations, respectively, on precipitation we have performed simulations with low $\mathrm{CCN}\left(N_{\mathrm{CN}}=100 \mathrm{~cm}^{-3}\right.$, $\left.\log (\sigma)=0.4, r_{2}=0.03 \mu \mathrm{m}, \epsilon=0.9\right)$ and high CCN assumptions $\left(N_{\mathrm{CN}}=3200 \mathrm{~cm}^{-3}, \log (\sigma)=0.2, r_{2}=0.03 \mu \mathrm{m}, \epsilon=0.7\right.$, cf. Table 1 of Noppel et al., 2010).

Heterogeneous ice nucleation of aerosol particles to IN is parameterized following Phillips et al. (2008, PDA08 hereafter) and the parameters given there serve as our standard configuration called "low IN". Further experiments with an increase (decrease) of IN by one order in magnitude are performed as "high IN" ("very low IN") sensitivity studies. The dependency of the number of activated IN by immersion freezing on temperature is shown in Fig. 2. For the present study, the details of the ice nucleation scheme are in fact rather unimportant, i.e. it does not make any difference whether the IN are due to soot, dust or organics. Nevertheless, we have used the PDA08 scheme, because it

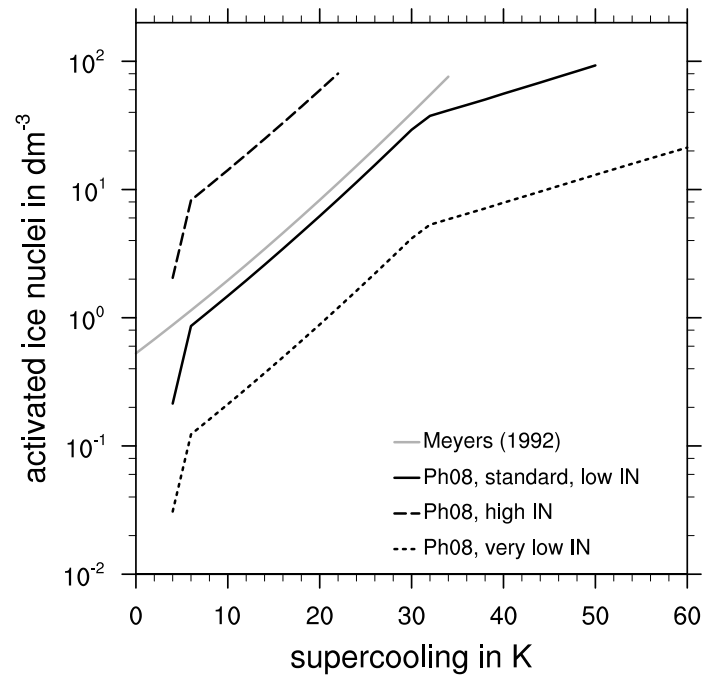

Fig. 2. Number density of activated ice nuclei (IN) as a function of supercooling in K. Shown are the relations for the Phillips et al. (2008) parameterization with three different aerosol assumptions, and the Meyers et al. (1992) parameterization.

compares well with recent observations (Eidhammer et al., 2009, 2010), and would allow a coupling with a prognostic aerosol model in the future. Deposition nucleation is taken into account in PDA08, but does not seem to play a major role in our simulations. Contact nucleation is neglected. 
The immersion freezing of raindrops is parameterized by a volume-dependent empirical relation (see Seifert and Beheng, 2006a). The coefficients of this parameterization are re-scaled depending on the assumed IN concentration. Activated heterogeneous IN are limited to 100 per liter in all simulations.

Ice nucleation via homogeneous freezing of aqueous solution droplets has recently also been included in the SB microphysics scheme following Kärcher and Lohmann (2002) and Kärcher et al. (2006). The competition of heterogeneous and homogeneous ice nucleation is explicitly taken into account, i.e. the reduction of the supersaturation over ice by pre-existing ice particles due to heterogeneous nucleation is rewritten in terms of a reduction of the vertical velocity which then leads to a smaller number of homogeneously nucleated particles (Kärcher et al., 2006). The radius of the aqueous solution droplets is assumed as $r_{\mathrm{hom}}=0.25 \mu \mathrm{m}$ but, as shown by Kärcher and Lohmann (2002), homogeneous nucleation depends primarily on the updraft velocity, and is rather insensitive to the details of the aerosol size distribution.

Note that we do not apply a prognostic aerosol model in this study, i.e. the CCN and IN perturbation experiments do only vary as constant "background" aerosol. Effects and feedbacks like scavenging, cloud chemistry etc. are not modeled. Nevertheless, this approach can be used to investigate the effect of order-in-magnitude changes in aerosol particle concentrations.

\subsection{Numerical simulations}

We have performed hindcasts for June, July, August (JJA) of the years 2008, 2009 and 2010. For each day simulations have been initialized at 00:00 UTC and 12:00 UTC from the operational COSMO-DE analysis and run for $48 \mathrm{~h}$. The extended simulation time of $48 \mathrm{~h}$ (compared to only $21 \mathrm{~h}$ of the operational COSMO-DE forecasts) was used to identify spin-up effects in the simulations which would point towards unbalanced initial or boundary conditions or problems in the model physics.

We performed a set of hindcasts with the operational system and six sensitivity experiments using the two-moment microphysics with high and low CCN, as well as low, high, and very low IN (Table 3). This sums up to 3864 individual simulations. Hourly output was saved including most threedimensional variables like cloud and precipitation mixing ratios, number concentrations, vertical velocity etc.

\section{Results}

\subsection{Analysis}

Here we focus on the statistical behavior of the model and the response of clouds and precipitation to the changes in $\mathrm{CCN}$ and IN assumptions. More detailed analysis and validation is
Table 3. Experiments performed for this study. The data can be accessed from DWD using the database IDs given here for individual experiments and years.

\begin{tabular}{|c|c|c|c|c|c|c|}
\hline \multirow[t]{2}{*}{ No. } & \multicolumn{3}{|c|}{ ID in database } & \multirow{2}{*}{$\begin{array}{l}\text { microphysics } \\
\text { scheme }\end{array}$} & \multirow[t]{2}{*}{$\mathrm{CCN}$} & \multirow[t]{2}{*}{ IN } \\
\hline & 2008 & 2009 & 2010 & & & \\
\hline 1 & 7544 & 7451 & 7895 & two-moment & high & low \\
\hline 2 & 7545 & 7452 & 7899 & two-moment & low & low \\
\hline 3 & 7547 & 7454 & 7954 & two-moment & high & high \\
\hline 4 & 7907 & 7906 & 7955 & two-moment & low & high \\
\hline 5 & 7546 & 7453 & 8013 & two-moment & high & very low \\
\hline 6 & 8056 & 8055 & 8026 & two-moment & low & very low \\
\hline 7 & 7483 & 7450 & 7897 & one-moment & - & - \\
\hline
\end{tabular}

planned in future, e.g. using remote sensing data as in Pfeifer et al. (2010).

As has been found in many previous studies of aerosol effects on clouds (Khain et al., 1999, 2005; Seifert et al., 2006), the mixing ratios of cloud water, cloud ice, graupel, etc. do change significantly in different $\mathrm{CCN}$ and IN regimes. The time series of the mean integrated water column of the cloud and precipitation species (Fig. 3) show an increase of more than a factor 2 in the cloud water path between low and high $\mathrm{CCN}$ assumptions, the snow water path increases, but cloud ice and graupel/hail decreases (Fig. 3a). This can be explained by the suppression of the warm rain processes in the high CCN regime: Due to the slow growth from cloud droplets to raindrops in a high $\mathrm{CCN}$ regime, cloud water is not as efficiently removed, hence, the larger cloud water content. An increase in IN, e.g. between experiments 1 and 3, leads to a reduction of the cloud water path, because cloud water freezes more efficiently, and consequently the snow water path increases (Fig. 3b).

Assumptions about CCN and IN do have a strong impact on the glaciation of mixed-phase clouds. Figure 4 shows the probability density function (PDF) of the ratio of ice water content IWC and total water content TWC, i.e. ice fraction IWC/TWC. The PDF is evaluated for a given temperature $T$ for mixed-phase clouds with cloud mixing ratio $q_{c}>0$ and TWC $>1 \times 10^{-6} \mathrm{~kg} \mathrm{~m}^{-3}$. The PDFs of the ice fraction for the six experiments with different CCN/IN assumption show that more IN do, as expected, lead to a more rapid, more efficient glaciation of the clouds. At high CCN, high IN conditions virtually all clouds are completely glaciated at $-25^{\circ} \mathrm{C}$, at lower IN concentrations significant liquid water may exist in updraft cores even at lower temperatures. Reducing $\mathrm{CCN}$ leads also to a more efficient glaciation, because drizzle drops and raindrops make the cloud freeze more rapidly due to the volume dependency of the freezing of such large drops. The different glaciation characteristics of the clouds depending on CCN/IN have a pronounced effect on the dynamics by modifying the latent heat release, and also affect the precipitation efficiency of the clouds. 
a) $\mathrm{CCN}$ sensitivity at low IN

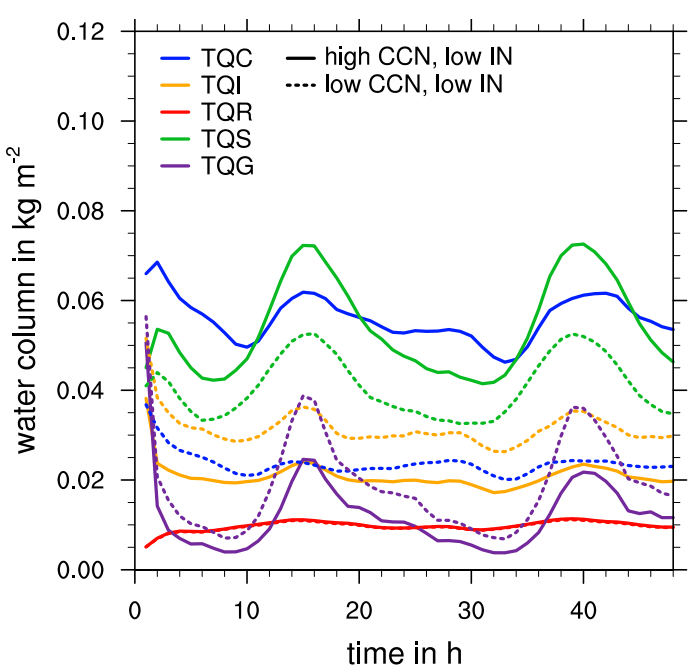

b) IN sensitivity at high $\mathrm{CCN}$

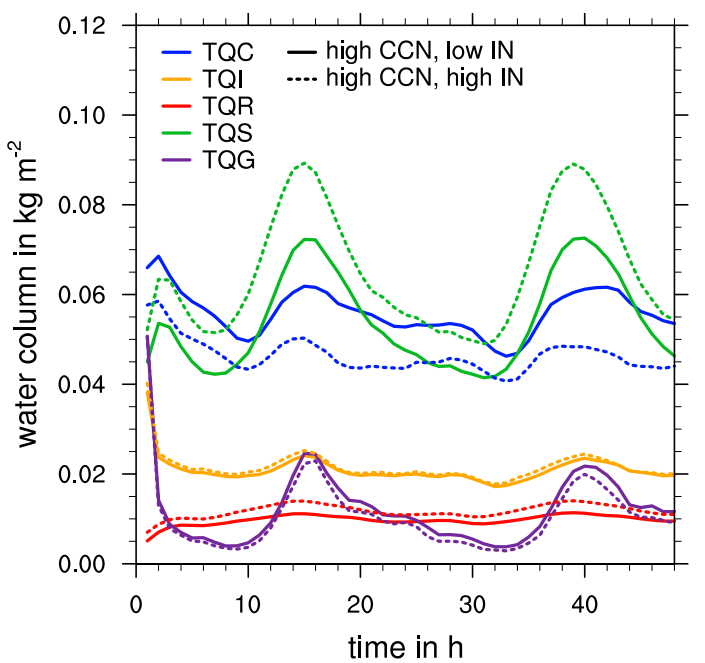

Fig. 3. Time series of integrated water path in $\mathrm{kg} \mathrm{m}^{-2}$, averaged over the evaluation domain and over all simulations of each experiment, comparing the CCN experiments at low IN (left), and IN perturbation experiments at high CCN (right). Abbreviations are TQC: cloud liquid water, TQI: cloud ice, TQR: rain, TQS: snow, TQG: graupel and hail.

Table 4. Area-averaged monthly mean accumulated precipitation amounts in mm for the domains denoted in Fig. 1, i.e. Germany, as well as southern, central, northern and full evaluation domain.

\begin{tabular}{cccccccc}
\hline No. & CCN & IN & Germany & southern domain & central domain & northern domain & full domain \\
\hline 1 & high & low & 83.9 & 99.8 & 77.2 & 71.7 & 82.9 \\
2 & low & low & 83.1 & 97.2 & 76.9 & 70.9 & 81.6 \\
3 & high & high & 86.2 & 103.0 & 78.7 & 73.3 & 85.0 \\
4 & low & high & 83.3 & 97.7 & 76.3 & 70.5 & 81.5 \\
5 & high & very low & 79.9 & 94.9 & 73.8 & 68.6 & 79.1 \\
6 & low & very low & 79.1 & 92.5 & 73.2 & 67.4 & 77.7 \\
7 & \multicolumn{2}{c}{ one-moment } & 79.4 & 91.3 & 71.2 & 70.2 & 77.6
\end{tabular}

So far we have seen that changing the assumed CCN/IN concentrations in the model does have a significant effect on the microstructure of the clouds, but how strongly does this modify the precipitation amounts at the surface? Figure 5 shows the monthly mean precipitation amounts for experiments ${ }^{2} 1-4$; area averages of monthly mean accumulated precipitation over different regions are given in Table 4 . The monthly accumulations are sampled from the simulations by using the 06:00-18:00 h simulation period of all hindcasts initialized at 00:00 and 12:00 UTC. The spatial pattern is largely driven by orography with the highest precipitation amounts in the Alpenvorland, i.e. the foothills of the Alps. Also the German lower mountain ranges, like the Black Forest, the Harz, etc., lead to a pronounced orographic precipitation effect.

The differences between the four experiments are subtle, but some effects are clearly visible, e.g. experiment 2 with

\footnotetext{
${ }^{2}$ The corresponding Figs. for Exps. 5-7, and observations are provided in the online supplement.
}

"low CCN" gives more precipitation at the Black Forest and the Harz compared to experiment 1 with "high CCN". This becomes much more obvious in Fig. 6 which shows the relative difference in monthly mean precipitation comparing different experiments. The $\mathrm{CCN}$ sensitivity correlates well with the mountain ranges like the Black Forest, the Brocken and the Röhn.

That the "low CCN" assumptions lead to more precipitation on the mountain ranges (Fig. 6a) is easily understood because the fast rain formation of a low CCN cloud is immediately coupled to the dynamical forcing of the orography while the much slower rain formation in a high CCN environment reduces the impact of mesoscale orographic obstacles. Interestingly, this increase of precipitation on the mountain top at "low CCN" is overcompensated by a decrease in the lee of the mountains, i.e. averaged over a larger area the "high CCN" experiments have slightly higher precipitation amounts than the corresponding "low CCN" simulations. IN sensitivities, on the other hand, do not correlate 
a) high $\mathrm{CCN}$, high IN

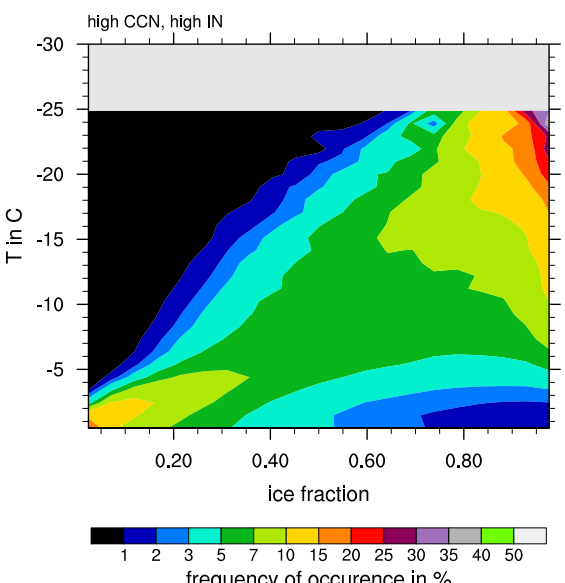

d) low $\mathrm{CCN}$, high IN

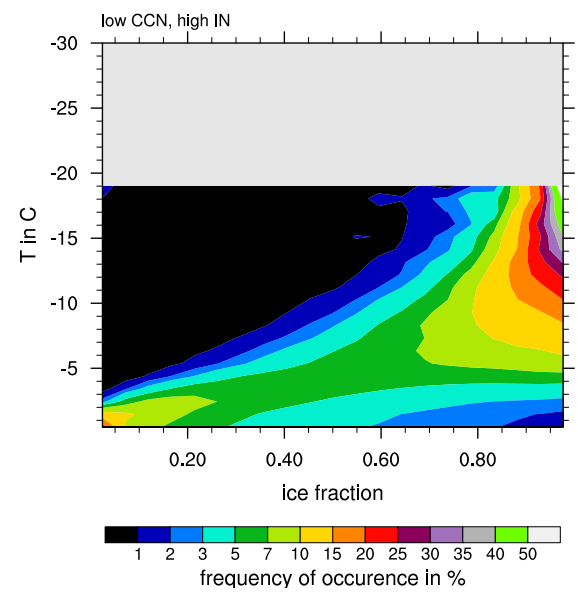

b) high CCN, low IN

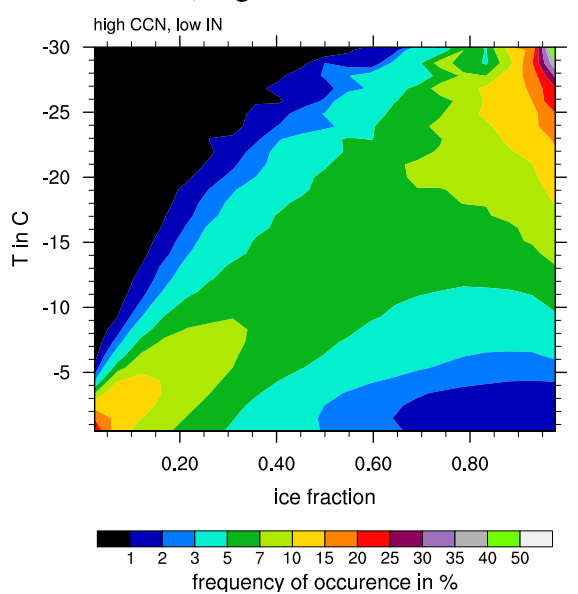

e) low $\mathrm{CCN}$, low IN

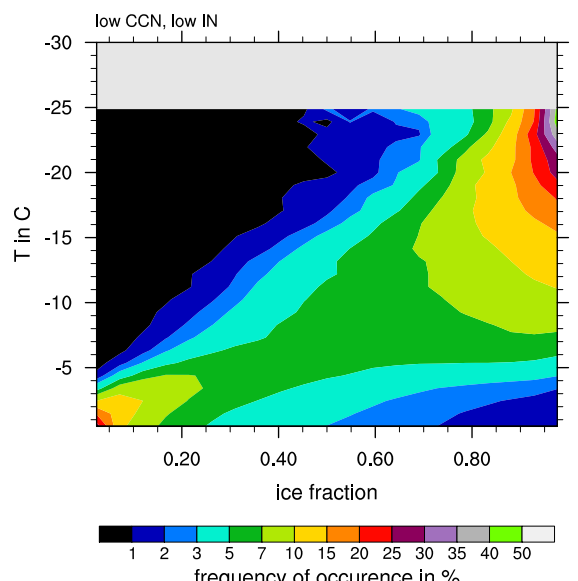

c) high $\mathrm{CCN}$, very low IN

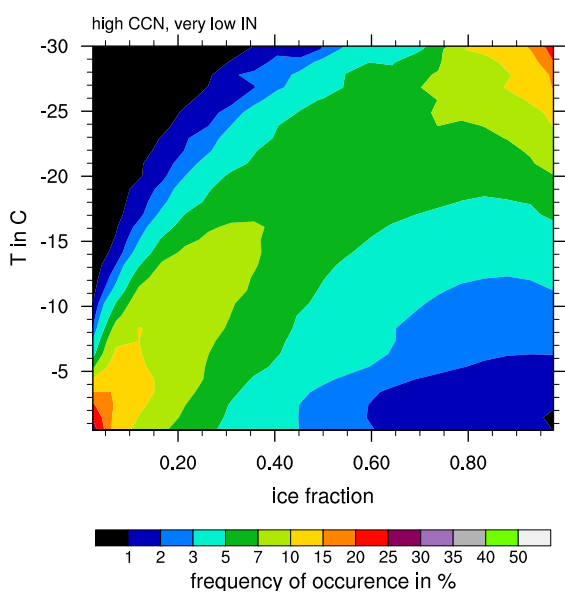

f) low $\mathrm{CCN}$, very low IN

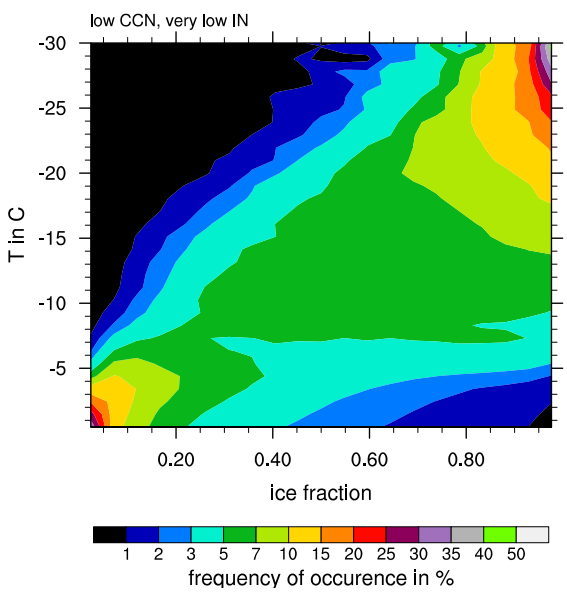

Fig. 4. Probability density function of ice fraction in mixed-phase clouds in $\%$ as a function of temperature. Shown are the six experiments with different CCN and IN assumptions. Data is from the full evaluation domain using 00:00 and 12:00 UTC simulations sampled every 3 hours from 6-15 h simulation time. Grey areas indicate insufficient number of mixed-phase grid points to calculate a probability density function.

much with the orography (Fig. 6c, d). Mixed-phase precipitation formation, especially during summertime, seems to be too slow, and is maybe too complex, to respond immediately to mesoscale orographic obstacles. Increasing the number of IN leads, on average, to an increase in precipitation amounts, especially for the "high CCN" assumptions (Fig. 6c, Table 4). The experiments with different $\mathrm{CCN}$ assumptions (Fig. 6a, b) show that "low $\mathrm{CCN}$ " leads to more rain in the western part, while "high CCN" increases precipitation in the eastern part. In a dominantly westerly flow this suggests that, in a low CCN environment, moist air masses rain out faster, and less moisture is transported eastwards over continental Europe, although some part of this effect might be an unphysical response to the lateral boundary conditions (cf. discussion in online suppl.). Before we go into the further details of the IN- and CCN-sensitivities, we extend the analysis to the mean diurnal cycle of hourly precipitation rate as given in Fig. 7.

During summer, daytime development of deep convection leads to a strong diurnal cycle in precipitation rate. The maximum is around 16:00 UTC when averaged over the full evaluation domain (Fig. 7a), and close to 18:00 UTC in the southern subdomain (Fig. 7b). The model is able to reproduce the diurnal cycle reasonably well as shown by the comparison to precipitation rates derived from radar data, and even the diurnal cycle on day two of the simulations is well captured. The model shows some spin-down, i.e. during the first $6 \mathrm{~h}$ of the simulation the precipitation rate is overestimated. This is to some extent due to the inconsistency of the initial condition: the operational COSMO-DE analysis uses the one-moment microphysics scheme which yields higher hydrometeor mixing ratios, especially for snow. Some part of the spin-down 
a) Experiment 1: high $\mathrm{CCN}$, low IN

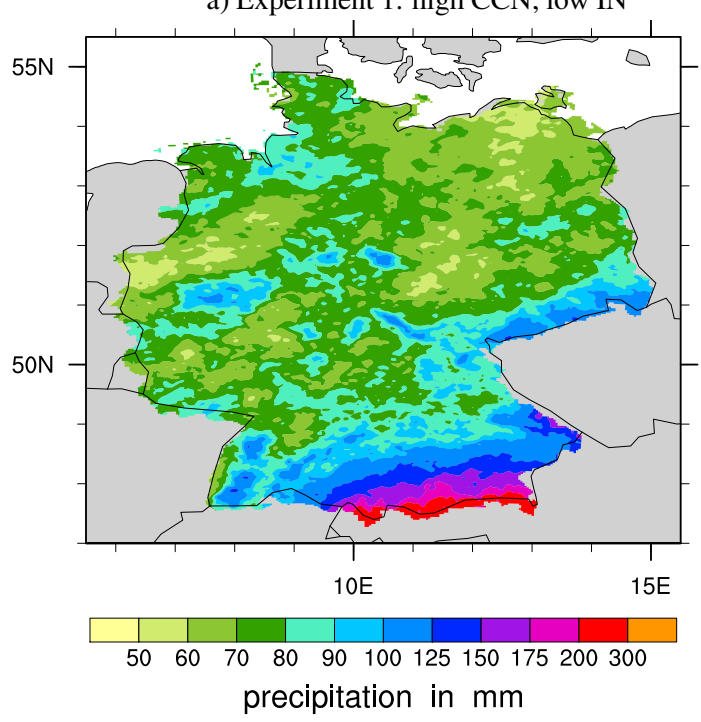

c) Experiment 3: high CCN, high IN

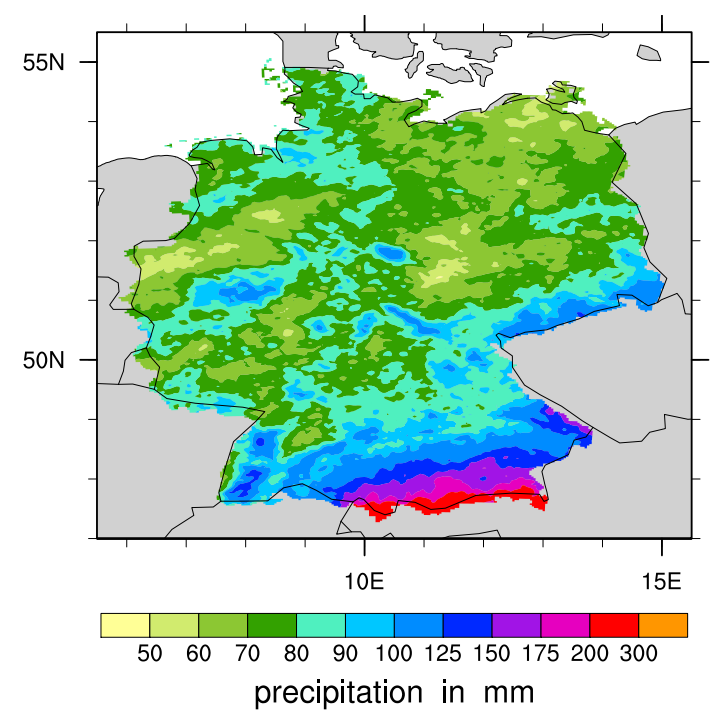

b) Experiment 2: low $\mathrm{CCN}$, low IN

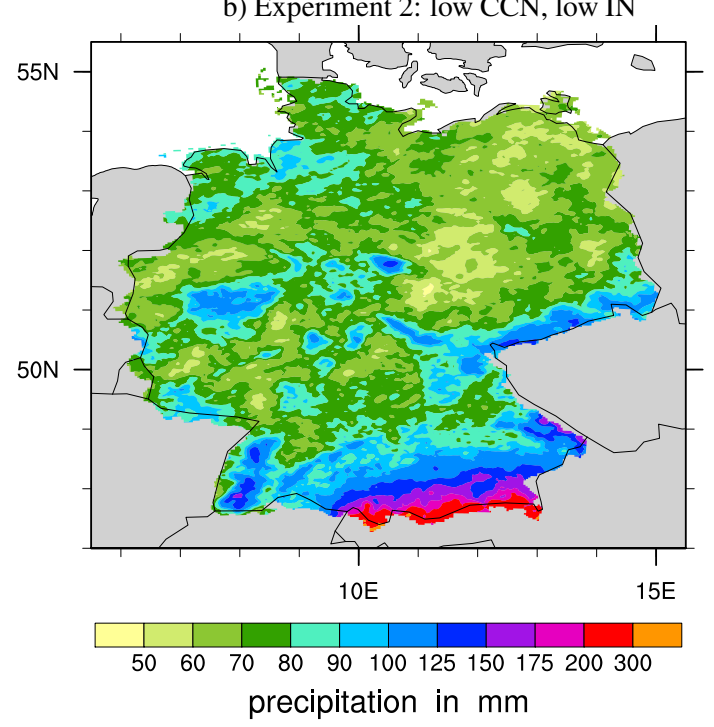

d) Experiment 4: low CCN, high IN

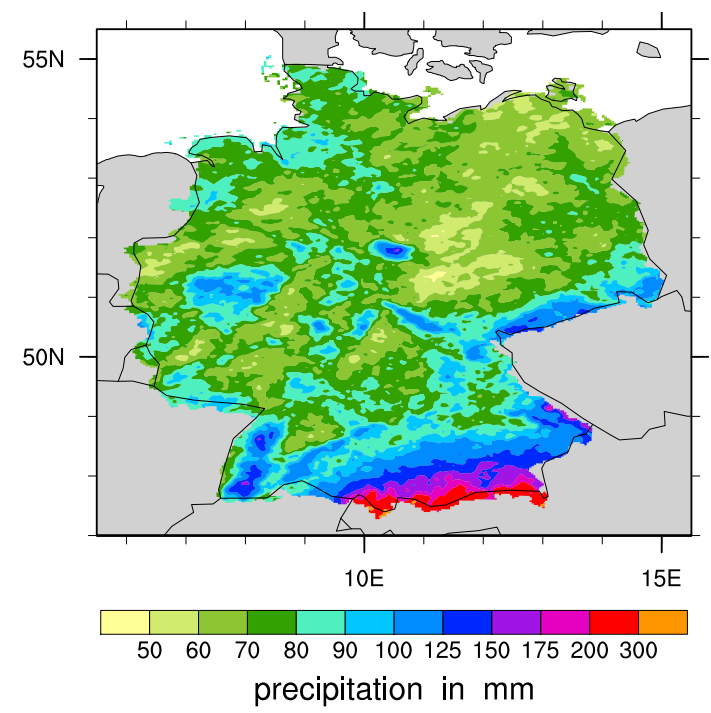

Fig. 5. Monthly mean precipitation amount of JJA 2008-2010 for experiments 1-4 combined from 06:00-18:00 h hindcasts initialized at 00:00 and 12:00 UTC.

can also be attributed to the latent heat nudging being too active during the night. This spin-down might affect the simulations and the CCN/IN sensitivities, but since the "day 2" shows similar behavior to "day 1 " we argue that those effect are small. The diurnal cycle analysis confirms the findings from the monthly mean accumulations, i.e. the effect of the CCN/IN assumptions is small and complex. For the "low IN" experiments with high and low CCN assumptions the mean diurnal cycles are very similar (the blue dotted and dashed lines fall onto each other in large parts). The same applies to the "very low IN" experiments (green lines), although they show a reduction of precipitation compared to the "low IN" experiments. For the "high IN" regime there is a significant difference between low and high $\mathrm{CCN}$ assumption with the high $\mathrm{CCN}$ case showing a stronger diurnal cycle (red lines). This difference in CCN sensitivity at different levels of IN concentrations is also revealed by Table 4 for the monthly mean precipitation accumulation. The high IN regime shows a stronger sensitivity to $\mathrm{CCN}$ (Exps. 3 vs. 4) than the simulations with "low" or "very low" IN assumptions (1 vs. 2, or 5 vs. 6).

The difference in the response to $\mathrm{CCN}$ changes at different levels of IN concentrations may be explained as follows. For clouds with high CCN an increase in IN can lead to a small but significant increase in surface precipitation, mostly because more condensate becomes available for collection 
a) Sensitivity to CCN (low-high) at low IN (Exp. 2 - Exp. 1)

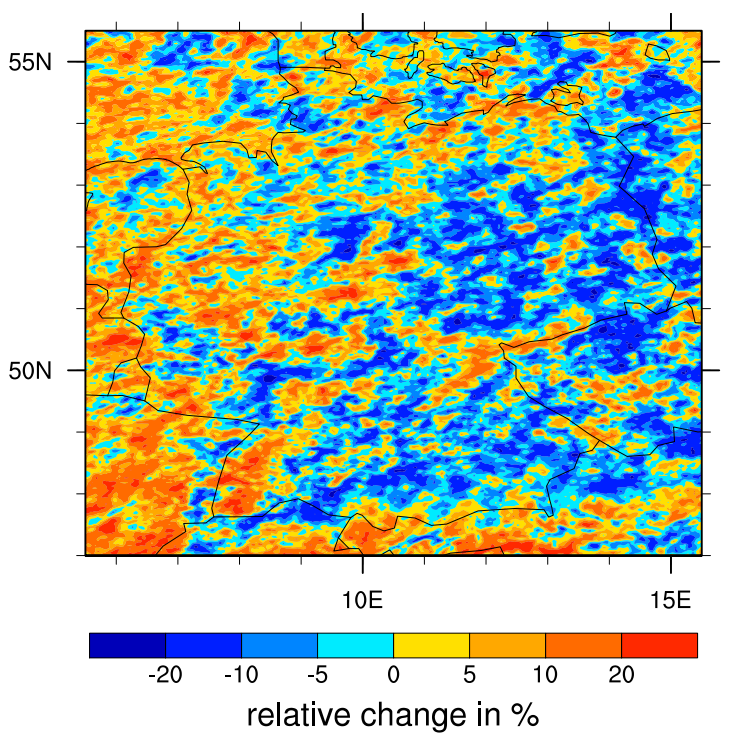

c) Sensitivity to IN (high-low) at high CCN (Exp. 3 - Exp. 1)

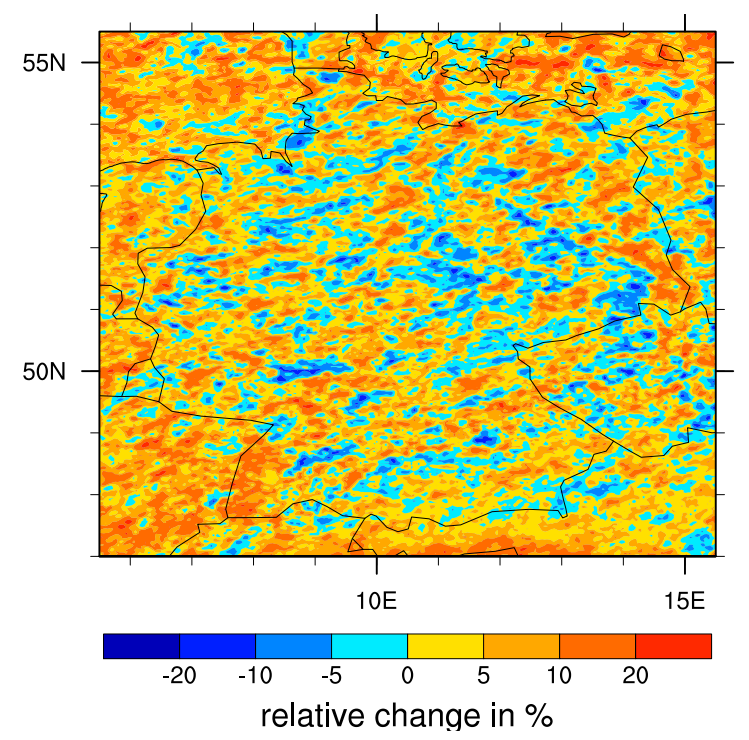

b) Sensitivity to CCN (low-high) at high IN (Exp. 4 - Exp. 3)

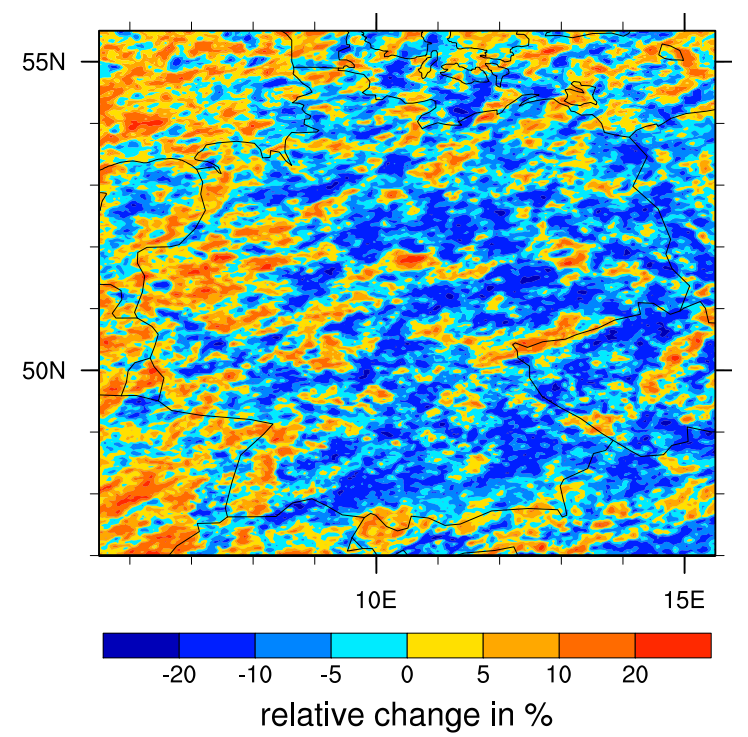

d) Sensitivity to IN (high-low) at low CCN (Exp. 4 - Exp. 2)

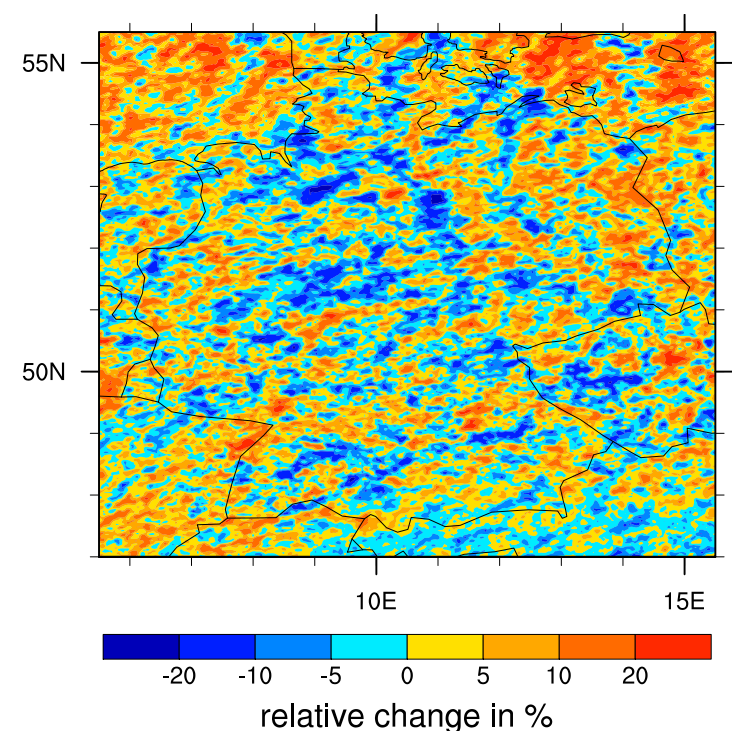

Fig. 6. Relative difference in \% of the monthly mean accumulated precipitation of JJA 2008-2010 comparing different experiments.

processes, and, due to the more efficient glaciation with increasing IN (cf. Fig. 4), more latent heat is released which invigorates the dynamics (see Fig. 8 and next paragraph). For clouds in a low $\mathrm{CCN}$ atmosphere, on the other hand, an increase in IN can lead to a decrease in surface precipitation (Teller and Levin, 2006). This behavior of the low CCN clouds can be explained by the fact that some part of the condensate rains out early by warm rain processes, leaving less condensate behind for the mixed-phase precipitation formation. Thus the mixed-phase region of the low CCN clouds is more likely to be dominated by microphysical bottlenecks, i.e. having small ice crystals which form precipitation more slowly. Adding IN to such a cloud can lead to a reduction of the precipitation efficiency. The opposite is true in a high $\mathrm{CCN}$ environment where mixed-phase processes are the only efficient rain formation mechanism. The balance between those feedbacks may differ from cloud to cloud, but, for example, in the evening hours (19:00-22:00 h simulation time) all experiments with "high CCN" show higher precipitation rates than their corresponding "low CCN" counterparts. A temporal shift in the diurnal cycle is most significant in case of the IN sensitivity, with lower IN numbers leading to a 
a) full evaluation domain

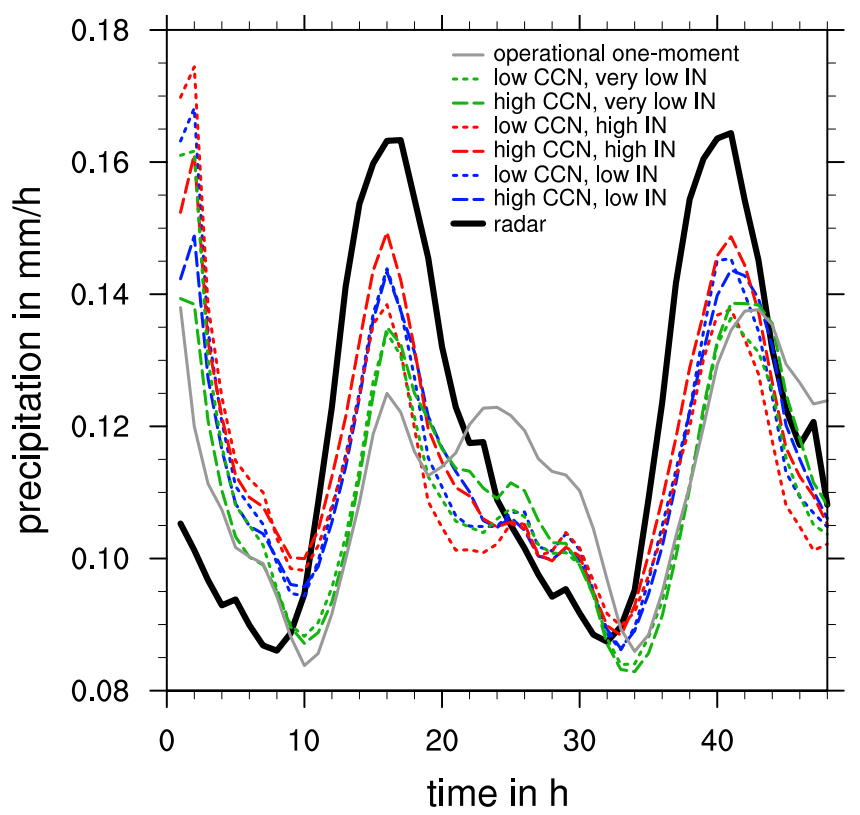

b) southern evaluation subdomain

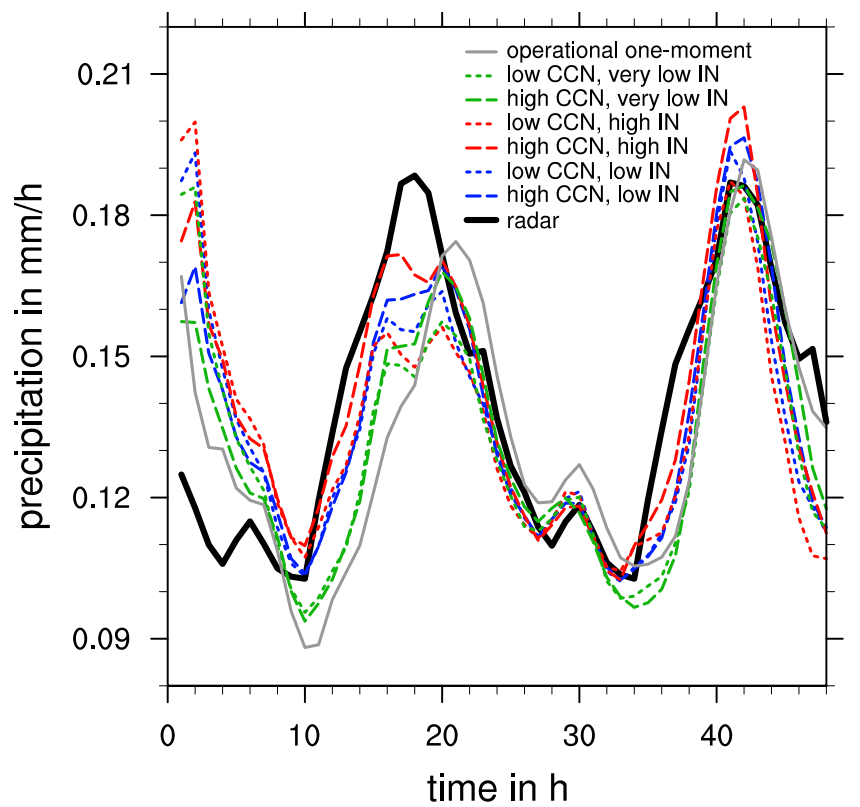

Fig. 7. Time series of hourly rain rate averaged over the (a) the full evaluation domain, and (b) the southern evaluation domain. Shown are the radar data, the six two-moment microphysics experiments, and the simulation using the operational one-moment scheme (all simulations initialized at 00:00 UTC).

delay in precipitation (this is most pronounced for the southern evaluation domain, Fig. 7b).

Further evidence for the invigoration of convective clouds in a high CCN environment is provided by an analysis of the convective cloud core depth (Fig. 8). Here the convective cloud core depth is defined as the height between cloud base and cloud top (given by a threshold of $q_{c}+q_{i}=10^{-3} \mathrm{~g} \mathrm{~kg}^{-1}$ ) of cloud cores with an maximum updraft velocity $w_{\max }>$ $1 \mathrm{~m} \mathrm{~s}^{-1}$ in the column and $q_{c}+q_{i}>0.5 \mathrm{~g} \mathrm{~kg}^{-1}$ at the location of the maximum updraft velocity. This shows that convection cores do indeed grow deeper in the "high CCN" environment compared to "low CCN". The cloud cores also become deeper when fewer IN are available for the glaciation of the cloud.

So far we have, for clarity and simplicity, only analyzed the (simulated) climatological mean summertime precipitation, either as monthly mean or as mean diurnal cycle. To extend the analysis to the variability of 12-h accumulated precipitation Fig. 9 provides a box-whisker plot of the statistics of area-averaged precipitation amounts. This shows, on one hand, that $\mathrm{CCN}$ or IN perturbations can induce a significant variability even on the meso- $\beta$-scale (as represented by the evaluation sub-domains), i.e. depending on the meteorological situation aerosol variations may lead to an increase or decrease of up to $20 \%$ in the 12 -h accumulated surface precipitation. On the other hand, some of the variability might be caused by relatively small spatial shifts of

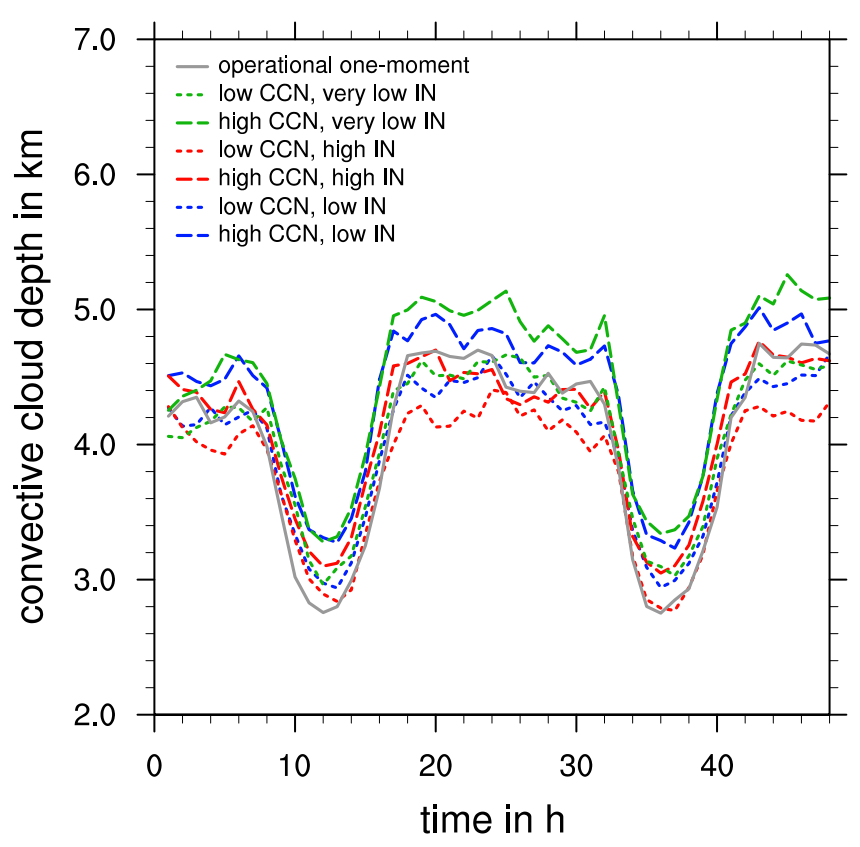

Fig. 8. Time series of convective cloud core depth averaged over the full evaluation domain for the different model experiments. 


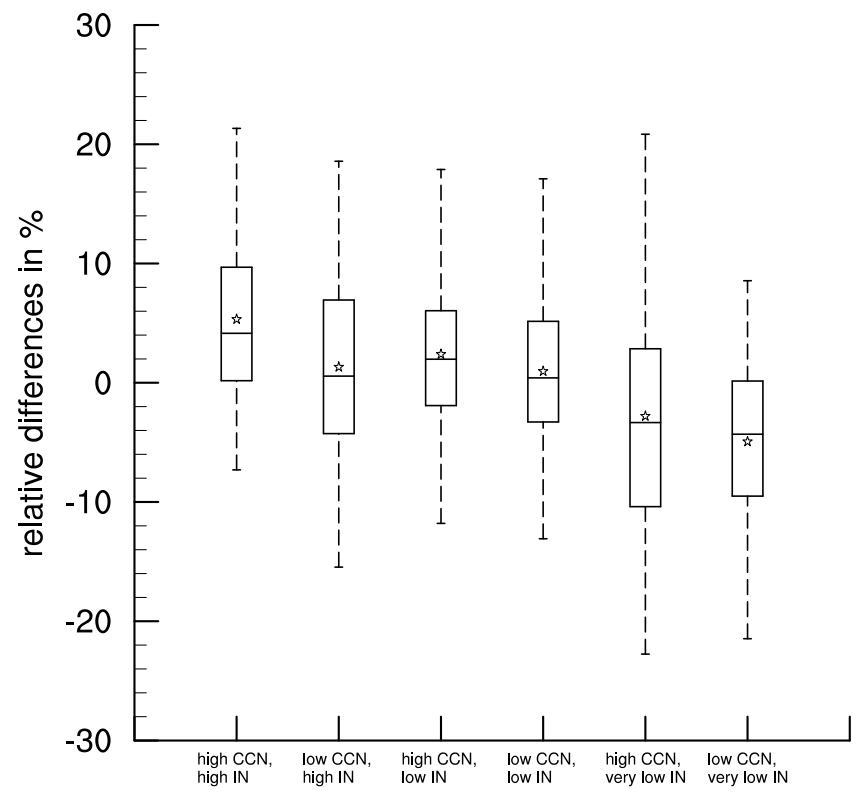

Fig. 9. Box-whisker plot of relative change of 12-h accumulated area-averaged precipitation of JJA 2008-2010. Shown are anomalies relative to the mean of Exps. 1-6. The precipitation data has been averaged over either one of the three subdomains. The bottom and top of the boxes are the lower and upper quartiles, the line near the middle of the boxes is the median, whiskers are the 5th and 95th percentiles and the stars represent the mean value.

precipitation systems into and out of the evaluation subdomains. The mean and median of the differences are small, most relevant is maybe the increase in precipitation between Exp. 3 (low CCN, high IN) and Exp. 4 (high CCN, high IN), which is much larger than the difference between Exps. 1 and 2. Both experiments with "very low IN" show a significant reduction in the 12 -h precipitation amounts. For most days the variability induced by the aerosol-microphysics perturbations, i.e. the spread of all 6 experiments, is smaller than $10 \%$. Compared to the uncertainty of measurements of area-averaged precipitation, and also compared to the uncertainties in NWP, this aerosol-induced variability is therefore small or even negligible.

\subsection{Buffering}

Our analysis confirms the concept of clouds as a buffered system (Stevens and Feingold, 2009). As we have shown, cloud depth acts as a macroscopic cloud buffer, i.e. by growing deeper the dynamical feedback counteracts the inefficient microphysics in high CCN (low IN) conditions. Following the concept of microscopic and macroscopic buffers as formulated by Stevens and Feingold (2009), we may also take a second look at Fig. 3: In this sense the strong response of the cloud and snow water path to changes in CCN (or IN) does not indicate a similar change in precipitation, but just the opposite. The cloud microstructure (as well as macrostruc-

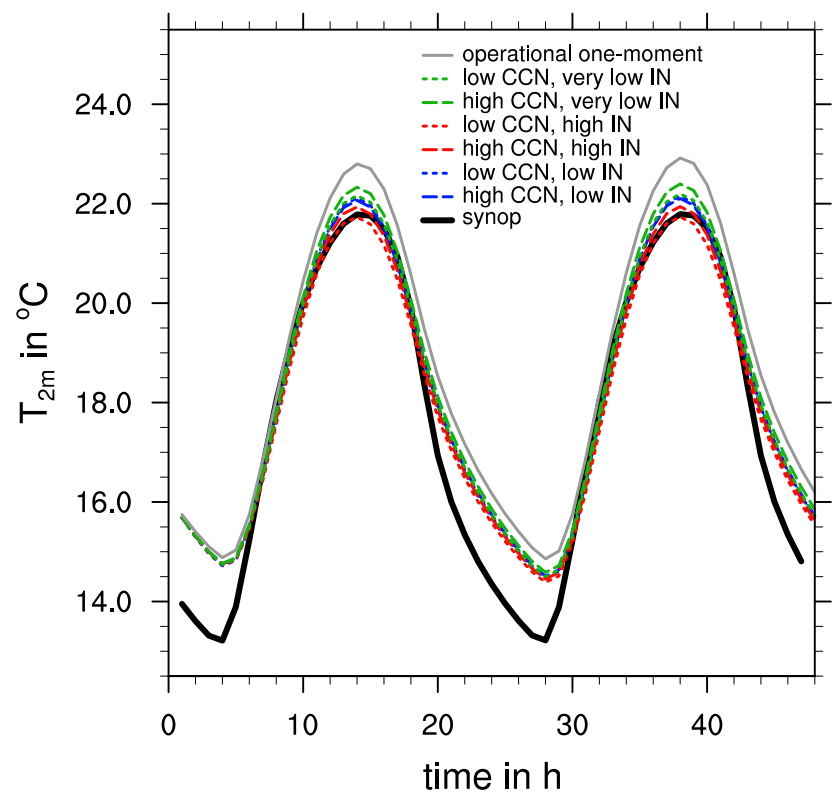

Fig. 10. Time series of $2 \mathrm{~m}$-temperature averaged over the full evaluation domain. Shown are synop measurements, the six twomoment microphysics experiments, and the simulation using the operational one-moment scheme.

ture) changes because the area-averaged precipitation rate is imposed by the large-scale forcing, and to counteract the slowed-down precipitation processes under high $\mathrm{CCN}$ conditions the cloud water path (and cloud depth) increases. The response to changes in IN is even more complex, because the microphysical sensitivity already depends on the microstructure on the cloud, i.e. increasing IN can either slow down or enhance precipitation formation depending on the cloud regime.

We have seen that aerosol effects on accumulated surface precipitation are small, and we have explained this by the micro- and macrophysical buffers. Does the near-surface temperature exhibit a similar robustness? To quantify the indirect aerosol effect in our simulations Fig. 10 shows the mean diurnal cycle of the $2 \mathrm{~m}$-temperature for the experiments 1-7. Compared to an average over all synop stations in the evaluation domain all simulations show a large warm bias during the night, which is caused by problems in the representation of the stable nocturnal boundary layer, a common and well-known problem in the COSMO model which is not relevant for aerosol-cloud effects. More interesting are the differences in the maximum $2 \mathrm{~m}$-temperature around noon. Different $\mathrm{CCN}$ and IN assumptions result in differences of about $0.5 \mathrm{~K}$ when averaged over the three summer seasons, i.e. differences on individual days can be much larger. This suggests that the radiative aerosol indirect effects are more relevant than effects on precipitation and are not as well buffered as the hydrological response of the system. The operational one-moment microphysics scheme leads to an even 
a) Simulation assuming 'low IN'

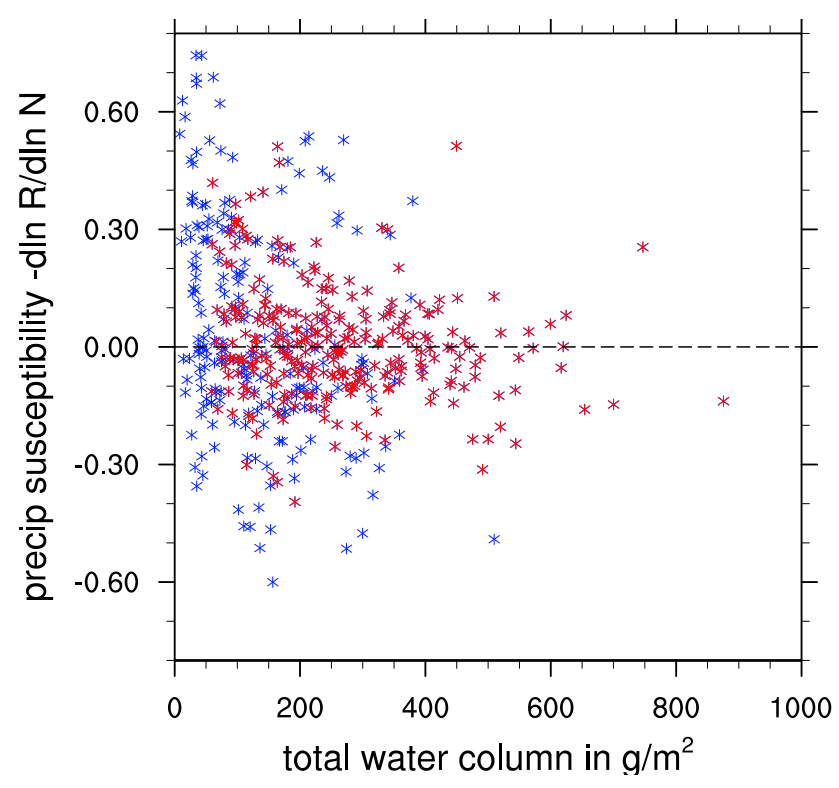

b) Simulation assuming 'high IN'

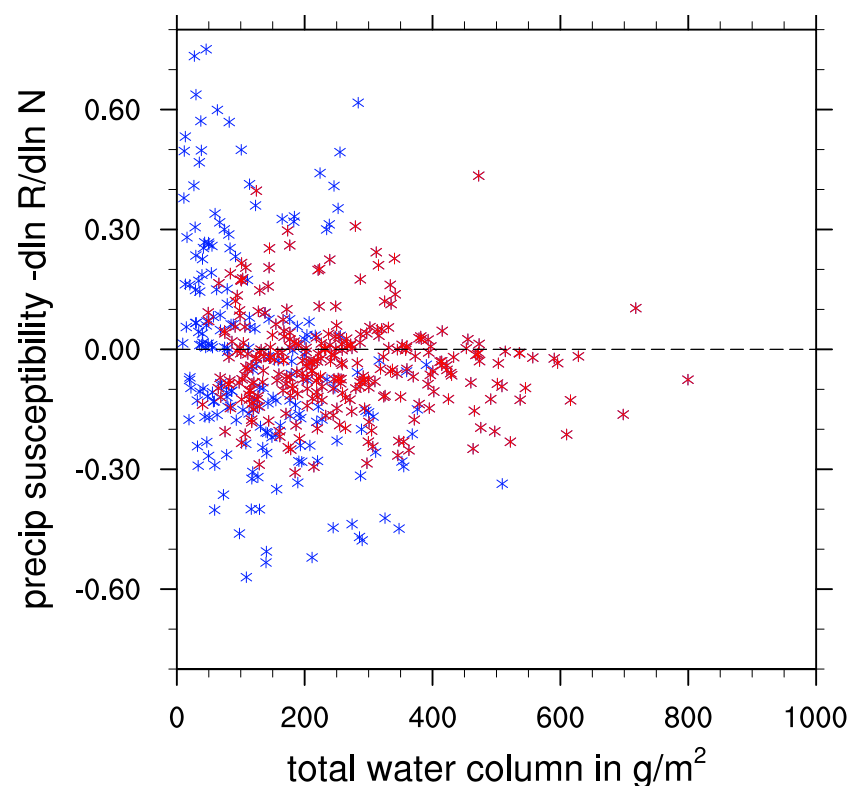

Fig. 11. Precipitation susceptibility to changes in $\mathrm{CCN}$ number for 12 -h area-averaged precipitation rate as a function of the total condensed water column (red markers indicate a precipitation amount exceeding $1 \mathrm{~mm}$, blue markers precipitation exceeding $0.1 \mathrm{~mm}$ ).

stronger positive bias in maximum $2 \mathrm{~m}$-temperature, and this difference between the two-moment simulations and the operational one-moment scheme may partly be explained by the different cloud-radiation coupling, which in case of the two-moment microphysics makes use of prognostic effective radii of cloud water and cloud ice.

\subsection{Regime dependency of susceptibility}

We have already seen that in a long-term average the precipitation amounts are robust to changes in aerosol assumptions, but are there cloud regimes that show a preferred susceptibility in either one direction? Following Feingold and Siebert (2009) and Sorooshian et al. $(2009,2010)$ we define the precipitation susceptibility to changes in aerosol concentration as

$S=-\frac{d \ln R}{d \ln N_{\mathrm{CN}}}$

i.e. the relative change in precipitation rate depending on $\mathrm{CN}$ number with the minus sign being a convention to get positive values of $S$ for a reduction of precipitation with increasing $\mathrm{CN}$ number. Here we specify $R$ as 12 -h area-averaged precipitation rate. In marine boundary layer clouds $S$ is positive (i.e. precipitation decreases with increased aerosol loading) and depends on liquid water path (LWP) with a maximum susceptibility for intermediate values of LWP (Sorooshian et al., 2009, 2010).

For our simulation of summertime mid-latitude precipitation $S$ scatters around zero (Fig. 11), corresponding to the overall robustness discussed above. The dependency on total water path (TWP) reveals only a decrease of $|S|$ for increasing TWP, something which can be explained by the fact that clouds with high water content are dominated by growth by accretion making them less susceptible to aerosol concentrations (Stevens and Feingold, 2009; Seifert and Stevens, 2010; Seifert and Zängl, 2010). The hydrologically more relevant events with $R>1 \mathrm{~mm} /(12 \mathrm{~h})$ show only a weak sensitivity to aerosol concentrations with $|S|$ below 0.3 for most events (Fig. 11a). Changing the IN assumptions from "low IN" to "high IN" results in a decrease of $S$ (Fig. 11b), especially for the stronger events with $R>1 \mathrm{~mm} /(12 \mathrm{~h})$. This, again, shows that for mixed-phase clouds the sensitivities to $\mathrm{CCN}$ and IN cannot easily be separated.

Seifert and Beheng (2006b) and others have postulated that certain regimes of deep convection, like multicells or supercells, which develop mostly as a function of CAPE and vertical wind shear, may show a different response to changes in aerosol properties. Figure 12 shows $S$ as a function of CAPE. "Low IN" simulations shows mostly positive values of $S$ for high CAPE (Fig. 12a), but the experiment with "high IN" (Fig. 12b) shows a more equal partitioning of $S$. Nevertheless, for the stronger events (red dots) with $R>1 \mathrm{~mm} /(12 \mathrm{~h})$ a weak increase of $S$ with CAPE is visible in both plots. The decrease of the variability of $|S|$ for larger CAPE might be explained by the high TWP in these cloud systems. Even when taking into account vertical wind shear (Fig. 13), here simply approximated by a wind speed in $5 \mathrm{~km}$ height above ground, it seems impossible to isolate distinct 

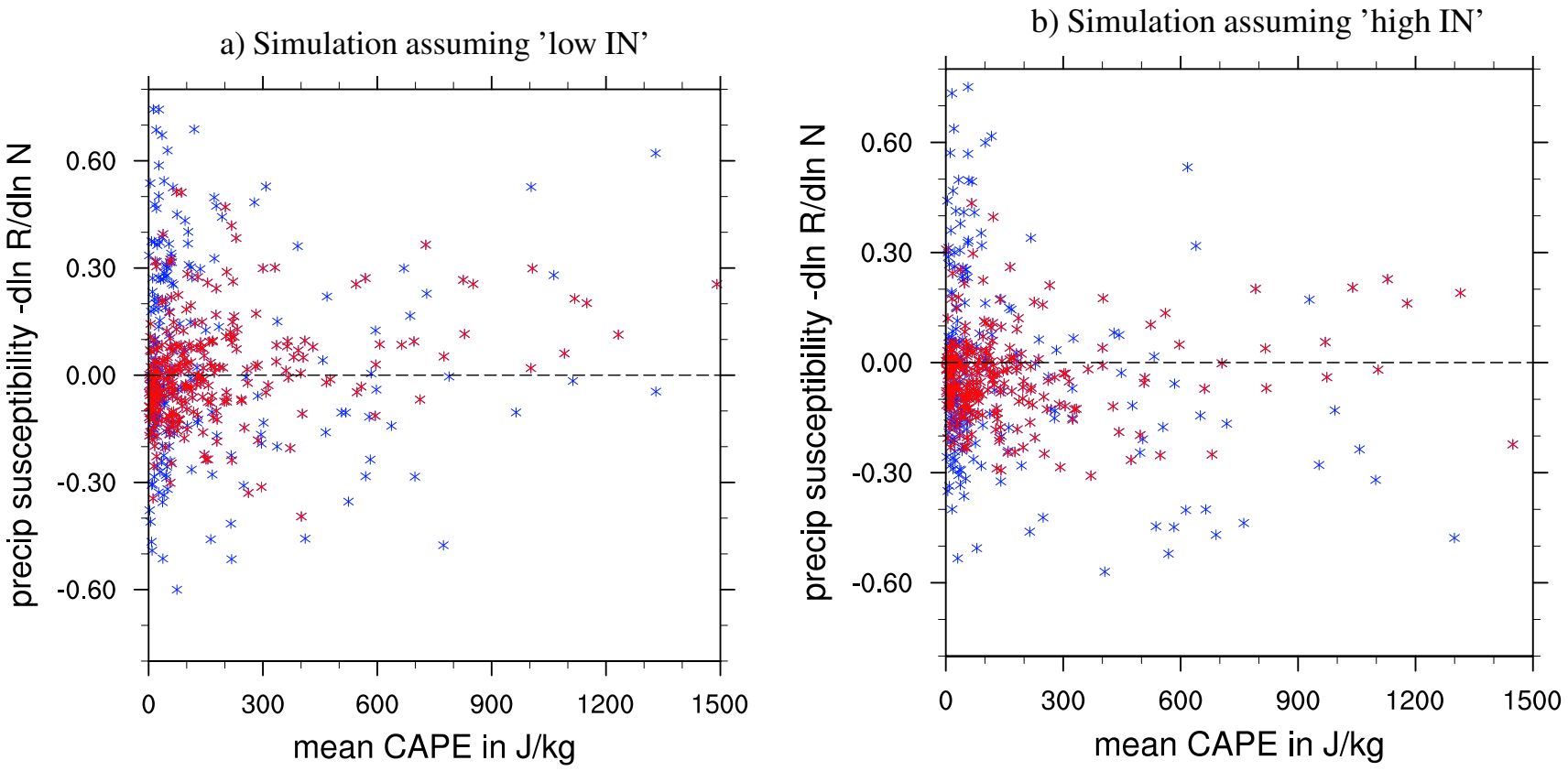

Fig. 12. As Fig. 11 showing the precipitation susceptibility to changes in CCN number for a 12-h area-averaged precipitation rate as a function of mean CAPE (averaged data of all three subdomains, red markers indicate a precipitation amount exceeding $1 \mathrm{~mm}$, blue markers precipitation exceeding $0.1 \mathrm{~mm})$.

a) Simulation assuming 'low IN'

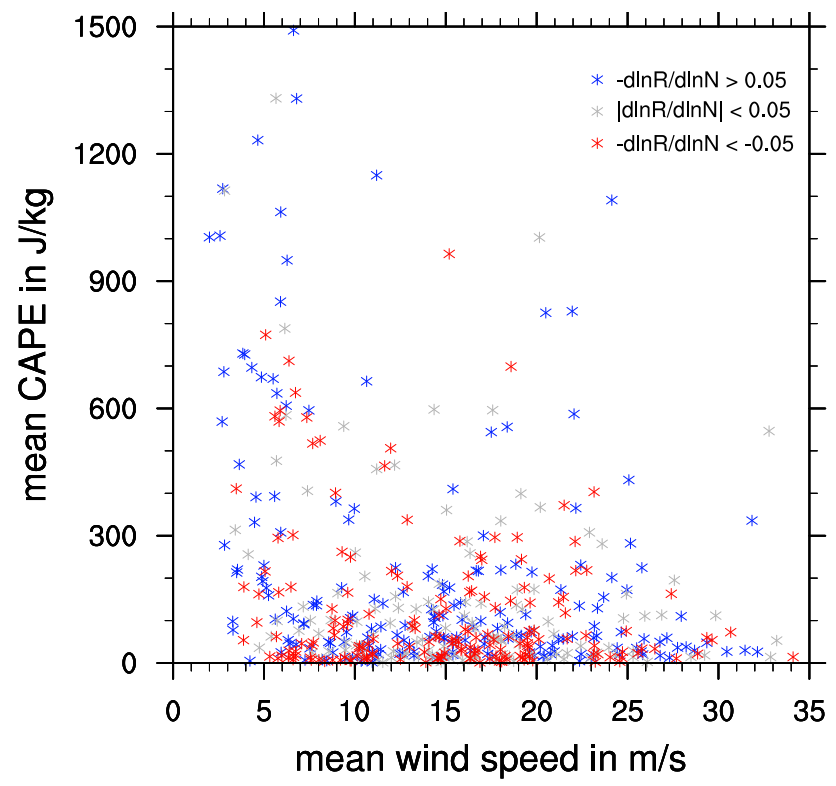

b) Simulation assuming 'high IN'

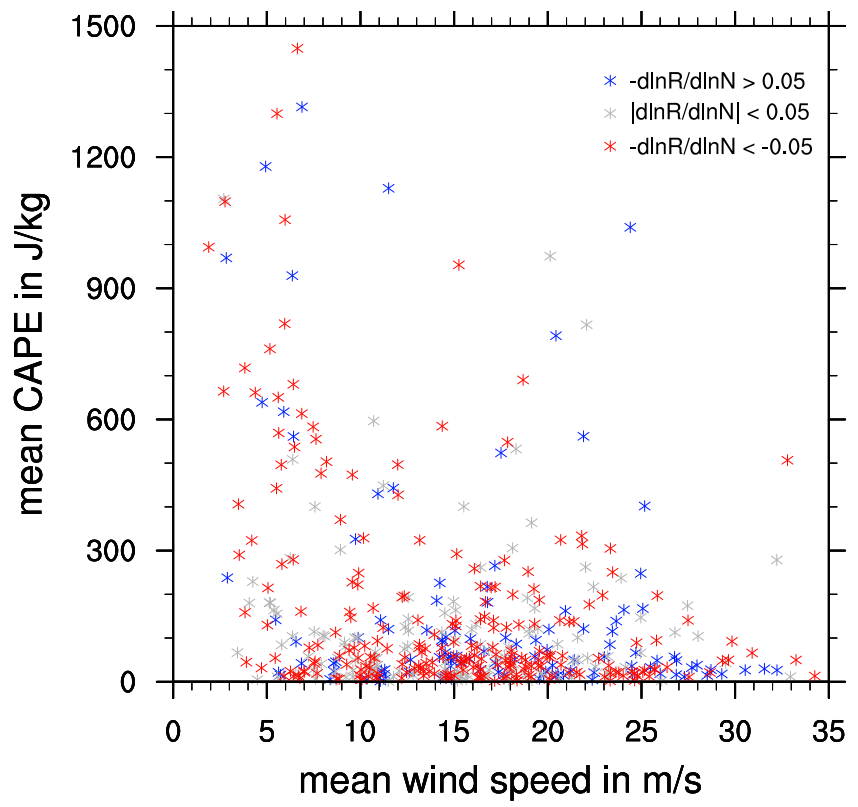

Fig. 13. Precipitation susceptibility to changes in $\mathrm{CCN}$ number for a $12-\mathrm{h}$ area-averaged precipitation rate as a function of mean CAPE and mean wind speed in $5 \mathrm{~km}$ height (averaged data over evaluation domain, blue markers indicate a positive susceptibility, red markers a negative susceptibility, grey markers low susceptibility). 
convective regimes as in Seifert and Beheng (2006b). Thus, although Fig. 13 is indeed an attempt to reproduce Fig. 12a of Seifert and Beheng (2006b) it fails to reveal a clear sensitivity to CAPE and wind shear in the COSMO data. The difficulties in isolating certain cloud regimes in the current study might to some extent be attributed to our coarse view of area-averaged $12 \mathrm{~h}$-accumulated precipitation amounts, in contrast to individual convective storms analysed by Seifert and Beheng (2006b). Maybe a more detailed investigation of some individual events could lead to a better understanding of the regime dependencies. This will be tackled in future studies.

\section{Conclusions}

We have presented a 3-yr climatology of aerosol effects on summertime precipitation over Germany as simulated by the COSMO model. The simulations make use of the COSMODE model setup which is an operational convective-scale numerical weather prediction model. A sophisticated twomoment microphysics scheme is applied to represent effects of order-in-magnitude aerosol perturbations on the accumulated surface precipitation. We find that, on average, the possible aerosol effects on 12-h accumulated area-averaged precipitation are small (below $5 \%$ for CCN, and below $10 \%$ for IN). This robustness of the precipitation confirms the concept of clouds as a buffered system as formulated by Stevens and Feingold (2009). Such a robustness has been found earlier by Grabowski et al. (1998) and also in recent studies (Grabowski and Morrison, 2011; van den Heever et al., 2011; Morrison and Grabowski, 2011). The advantage of our present study is in the application of a more realistic NWP-like model setup and a long time series, while all earlier and many recent studies use idealized and often two-dimensional model configurations, e.g. radiative-convective equilibrium, or focus on a few individual case studies.

Our results and their interpretation show that it might be useful to distinguish three different cloud buffering feedbacks:

1. In a high $\mathrm{CCN}$ environment the decrease in rain formation (autoconversion) can be compensated by an increase in liquid water content (LWC), i.e. the LWC increases until it yields a similar precipitation efficiency as in the clean CCN case.

2. Depending on environmental conditions other microphysical pathways take over if one microphysical process is strongly suppressed, e.g. mixed-phase processes become dominant when warm rain is suppressed in a polluted $\mathrm{CCN}$ regime at cold temperatures.

3. If the microphysical growth processes are suppressed, then dynamical feedbacks, e.g. an invigoration of convective dynamics, can compensate a slowed-down mi- crophysical precipitation formation, e.g. in polluted $\mathrm{CCN}$ case.

Those three types of buffers correspond to (1) the nonlinear character of the microphysics, (2) the complexity of the microphysical system with many possible process pathways, and (3) to the multi-scale coupled dynamics-microphysics nature of the system.

This study also shows that studying the aerosol impact on clouds based on single case studies or even individual clouds, as it is often done, can yield misleading results, because the important mesoscale feedbacks are not taken into account when using small domains and/or short time periods. Therefore the interpretation of such studies should be done very carefully, and simulation strategies that allow for such feedbacks should be preferred over approaches which do not.

The model setup of our study does also have some drawbacks, e.g. limited domain size and lateral-boundary conditions which are inconsistent with the aerosol/microphysics assumptions. There is no simple way around those problems of multiscale feedbacks, because larger domains become computationally expensive, and two-way nesting in a coarser model is not an option due to the problem to parameterize aerosol effects on deep convection. A possible alternative is the so-called multiscale modeling framework (MMF) also known as "super-parameterization" (Grabowski and Smolarkiewicz, 1999; Khairoutdinov and Randall, 2001; Tao et al., 2009; Wang et al., 2011).

In our simulations we do find a pronounced indirect aerosol effect on near-surface temperature with an amplitude of approximately $0.5 \mathrm{~K}$. Currently we see those results as preliminary, because of the lack of an in-depth validation of the cloud properties in our simulations. This needs further investigation, especially using a combination or high-resolution convective-scale modeling, as in the present study, with the use of remote sensing data to constrain the properties of the simulated cloud fields.

Possible or even necessary future research includes to repeat such a set of simulations with a regional climate model, i.e. instead of performing individual day-by-day simulations each summer would be run in one 3-month long simulation. This would allow for additional long-term feedbacks, but poses additional challenges for the model physics. Maybe even more important is to extend the model system to a full chemistry-aerosol-cloud model (e.g. by using the COSMOART framework of Vogel et al., 2009). Only such a complete modeling system would eventually allow a fully quantitative evaluation of the aerosol-cloud interaction. From an NWP perspective it would also be valuable to compare the variability and uncertainty introduced by the (unknown) aerosol distribution with other sources of uncertainty, e.g. by using the COSMO-DE ensemble prediction system (Gebhardt et al., 2010).

Nevertheless, we expect that the main result of this study, the robustness of the area-averaged precipitation amounts, 
will prove to be robust. We conclude that the effects of aerosols on precipitation are highly nonlinear, very complicated, hardly understood, highly variable and, when averaged over space and time, very small.

\section{Supplement related to this article is available online at: http://www.atmos-chem-phys.net/12/709/2012/ acp-12-709-2012-supplement.pdf.}

Acknowledgements. The contributions of Uli Blahak and Heike Noppel to the development and improvement of the two-moment microphysics scheme in the COSMO model are greatly acknowledged. Especially the vectorization of the code by U. B. has helped us considerably to carry out the present study. We thank Elias Zubler (ETH Zürich) for contributing the code for the improved cloud-radiation coupling of the two-moment scheme, and Vaughan Phillips for providing his code of the PDA08 ice nucleation scheme. Helpful and encouraging comments by Zev Levin on the analysis of the simulations are acknowledged, as are discussions within the COST Action ES0905. We thank Robert Pincus for comments which helped to improve the manuscript. Constructive comments by two anonymous reviewers are also acknowledged. DWD has provided the computer time for this project. C. K. has partly been funded by BMBF Grant klimazwei-01LS05114 "Umweltgerechte Flugroutenoptimierung (UFO)".

Edited by: B. Stevens

\section{References}

Albrecht, B.: Aerosols, cloud microphysics, and fractional cloudiness, Science, 245, 1227-1230, 1989.

Alpert, P., Halfon, N., and Levin, Z.: Does air pollution really suppress precipitation in Israel?, J. Appl. Meteorol., 47, 933-943, 2008.

Ayers, G. and Levin, Z.: Air pollution and precipitation, in: Clouds in the perturbed climate system, edited by Heintzenberg, J. and Charlson, R., 369-400, The MIT Press, 2009.

Baldauf, M., Seifert, A., Förstner, J., Majewski, D., and Raschendorfer, M.: Operational convective-scale numerical weather prediction with the COSMO model: description and sensitivities, Mon. Weather Rev., 139, 3887-3905, 2011.

Blahak, U.: Towards a better representation of high density ice particles in a state-of-the-art two-moment bulk microphysical scheme, in: Proc. 15th Int. Conf. Clouds and Precip., Cancun, Mexico, 2008.

Borys, R., Lowenthal, D., and Cohn, S.: Mountaintop and radar measurements of anthropogenic aerosol effects on snow growth and snowfall rate, Geophys. Res. Lett., 30, 1538, doi:10.1029/2002GL016855, 2003.

Cotton, W.: Modification of precipitation from warm clouds - a review, B. Am. Meteorol. Soc., 63, 146-160, 1982.

Cotton, W.: Weather and climate engineering, in: Clouds in the perturbed climate system, edited by: Heintzenberg, J. and Charlson, R., 369-400, The MIT Press, 2009.

Edwards, J. M., Havemann, S., Thelen, J. C., and Baran, A. J.: A new parametrization for the radiative properties of ice crystals:
Comparison with existing schemes and impact in a GCM, Atmos. Res., 83, 19-35, 2007.

Eidhammer, T., DeMott, P. J., and Kreidenweis, S. M.: A comparison of heterogeneous ice nucleation parameterizations using a parcel model framework, J. Geophys. Res., 114, D06202, doi:10.1029/2008JD011095, 2009.

Eidhammer, T., DeMott, P. J., Prenni, A. J., Petters, M. D., Twohy, C. H., Rogers, D. C., Stith, J., Heymsfield, A., Wang, Z., Pratt, K. A., Prather, K. A., Murphy, S. M., Seinfeld, J. H., Subramanian, R., and Kreidenweis, S. M.: Ice Initiation by Aerosol Particles: Measured and predicted ice nuclei concentrations versus measured ice crystal concentrations in an orographic wave cloud, J. Atmos. Sci., 67, 2417-2436, 2010.

Fan, J., Yuan, T., Comstock, J. M., Ghan, S., Khain, A., Leung, L. R., Li, Z., Martins, V. J., and Ovchinnikov, M.: Dominant role by vertical wind shear in regulating aerosol effects on deep convective clouds, J. Geophys. Res., 114, D22206, doi:10.1029/2009JD012352, 2009.

Feingold, G. and Siebert, H.: Cloud-aerosol interactions from the micro to the cloud scale, in: Clouds in the perturbed climate system: their relationship to energy balance, atmospheric dynamics, and precipitation, edited by: Heintzenberg, J. and Charlson, R. J., 319-338, 2009.

Garstang, M., Bruintjes, R., Serafin, R., Orville, H., Boe, B., Cotton, W., and Warburton, J.: Weather modification: finding common ground, B. Am. Meteorol. Soc., 86, 647-655, 2005.

Gebhardt, C., Theis, S., Paulat, M., and Ben Bouallegue, Z.: Uncertainties in COSMO-DE precipitation forecasts introduced by model perturbations and variation of lateral boundaries, Atmos. Res., 100, 168-177, doi:10.1016/j.atmosres.2010.12.008, 2010.

Grabowski, W. and Smolarkiewicz, P.: CRCP: a cloud resolving convection parameterization for modeling the tropical convecting atmosphere, Phys. D, 133, 171-178, 1999.

Grabowski, W., Wu, X., Moncrieff, M., and Hall, W.: Cloudresolving modeling of cloud systems during phase III of GATE. Part II: fffects of resolution and the third spatial dimension, J. Atmos. Sci., 55, 3264-3282, 1998.

Grabowski, W. W. and Morrison, H.: Indirect impact of atmospheric aerosols in idealized simulations of convective-radiative quasi equilibrium. Part II: double-moment microphysics, J. Climate, 24, 1897-1912, doi:10.1175/2010JCLI3647.1, 2011.

$\mathrm{Hu}$, Y. and Stamnes, K.: An accurate parameterization of the radiative properties of water clouds suitable for use in climate models, J. Climate, 6, 728-742, 1993.

Kärcher, B. and Lohmann, U.: A parameterization of cirrus cloud formation: Homogeneous freezing of supercooled aerosols, J. Geophys. Res., 107, 4010, doi:10.1029/2001JD000470, 2002.

Kärcher, B., Hendricks, J., and Lohmann, U.: Physically based parameterization of cirrus cloud formation for use in global atmospheric models, J. Geophys. Res., 111, D01205, doi:10.1029/2005JD006219, 2006.

Khain, A., Pokrovsky, A., and Sednev, I.: Some effects of cloudaerosol interaction on cloud microphysics structure and precipitation formation: Numerical experiments with a spectral microphysics cloud ensemble model, Atmos. Res., 52, 195-220, 1999.

Khain, A., Rosenfeld, D., and Pokrovsky, A.: Aerosol impact on the dynamics and microphysics of deep convective clouds, Q. J. Roy. Meteorol. Soc., 131, 2639-2663, 2005. 
Khairoutdinov, M. and Randall, D.: A cloud resolving model as a cloud parameterization in the NCAR community climate system model: preliminary results, Geophys. Res. Lett., 28, 3617-3620, 2001.

Koren, I., Kaufman, Y., Rosenfeld, D., Remer, L., and Rudich, Y.: Aerosol invigoration and restructuring of Atlantic convective clouds, Geophys. Res. Lett., 32, L14828, doi:10.1029/2005GL023187, 2005.

Levin, Z. and Cotton, W.: Aerosol pollution impact on precipitation: a scientific review, Springer, Heidelberg, WMO and IUGG Report, 2008.

Lohmann, U.: A glaciation indirect aerosol effect caused by soot aerosols, Geophys. Res. Lett., 29, 1052, doi:10.1029/2001GL014357, 2002.

Lohmann, U. and Feichter, J.: Global indirect aerosol effects: a review, Atmos. Chem. Phys., 5, 715-737, doi:10.5194/acp-5-7152005, 2005

Lohmann, U. and Hoose, C.: Sensitivity studies of different aerosol indirect effects in mixed-phase clouds, Atmos. Chem. Phys., 9, 8917-8934, doi:10.5194/acp-9-8917-2009, 2009.

Majewski, D., Liermann, D., Prohl, P., Ritter, B., Buchhold, M., Hanisch, T., Paul, G., Wergen, W., and Baumgardner, J.: The operational global Icosahedral-Hexagonal Gridpoint Model GME: description and high-resolution tests, J. Atmos. Sci., 139, 319338, 2002.

Morrison, H. and Grabowski, W. W.: Cloud-system resolving model simulations of aerosol indirect effects on tropical deep convection and its thermodynamic environment, Atmos. Chem. Phys., 11, 10503-10523, doi:10.5194/acp-11-10503-2011, 2011.

Noppel, H., Blahak, U., Seifert, A., and Beheng, K. D.: Simulations of a hailstorm and the impact of $\mathrm{CCN}$ using an advanced twomoment cloud microphysical scheme, Atmos. Res., 96, 286-301, 2010

Pfeifer, M., Yen, W., Baldauf, M., Craig, G., Crewell, S., Fischer, J., Hagen, M., Huehnerbein, A., Mech, M., Reinhardt, T., Schroeder, M., and Seifert, A.: Validating precipitation forecasts using remote sensor synergy: A case study approach, Meteorol. Zeitschr., 19, 601-617, 2010.

Phillips, V. T. J., DeMott, P. J., and Andronache, C.: An empirical parameterization of heterogeneous ice nucleation for multiple chemical species of aerosol, J. Atmos. Sci., 65, 2757-2783, 2008.

Rosenfeld, D. and Givati, A.: Evidence of orographic precipitation suppression by air pollution-induced aerosols in the western United States, J. Appl. Meteorol., 45, 893-911, 2006.

Segal, Y. and Khain, A.: Dependence of droplet concentration on aerosol conditions in different cloud types: Application to droplet concentration parameterization of aerosol conditions, J. Geophys. Res., 111, D15204, doi:10.1029/2005JD006561, 2006

Seifert, A.: A note on the shape-slope relation of the drop size distribution in convective rain, J. Appl. Meteorol., 44, 1146-1151, 2005.

Seifert, A.: On the parameterization of evaporation of raindrops as simulated by a one-dimensional rainshaft model, J. Atmos. Sci., 65, 3608-3619, 2008

Seifert, A. and Beheng, K.: A two-moment cloud microphysics parameterization for mixed-phase clouds. Part I: model description, Meteorol. Atmos. Phys., 92, 45-66, 2006a.
Seifert, A. and Beheng, K.: A two-moment cloud microphysics parameterization for mixed-phase clouds. Part II: maritime vs. continental deep convective storms, Meteorol. Atmos. Phys., 92, 67-88, 2006b.

Seifert, A. and Beheng, K. D.: A double-moment parameterization for simulating autoconversion, accretion and selfcollection, Atmos. Res., 59-60, 265-281, 2001.

Seifert, A. and Stevens, B.: Microphysical scaling relations in a kinematic model of isolated shallow cumulus clouds, J. Atmos. Sci., 67, 1575-1590, 2010.

Seifert, A. and Zängl, G.: Scaling relations in warm-rain orographic precipitation, Meteorol. Zeitschr., 19, 417-426, 2010.

Seifert, A., Khain, A., Pokrovsky, A., and Beheng, K. D.: A comparison of spectral bin and two-moment bulk mixed-phase microphysics, Atmos. Res., 80, 46-66, 2006.

Solomon, S., Qin, D., Manning, M., Chen, Z., Marquis, M., Averyt, K., Tignor, M., and Miller, H., eds.: Climate Change 2007: The physical science basis. contribution of working Group I to the fourth assessment report of the intergovernmental panel on climate change, chap. 7.5.2, Cambridge University Press, Cambridge, UK and New York, NY, USA, 2007.

Sorooshian, A., Feingold, G., Lebsock, M. D., Jiang, H., and Stephens, G. L.: On the precipitation susceptibility of clouds to aerosol perturbations, Geophys. Res. Lett., 36, L13803, doi:10.1029/2009GL038993, 2009.

Sorooshian, A., Feingold, G., Lebsock, M. D., Jiang, H. and Stephens, G. L.: Deconstructing the precipitation susceptibility construct: Improving methodology for aerosolcloud precipitation studies, J. Geophys. Res., 115, D17201, doi:10.1029/2009JD013426, 2010.

Stephan, K., Klink, S., and Schraff, C.: Assimilation of radarderived rain rates into the convective-scale model COSMO-DE at DWD, Q. J. Roy. Meteorol. Soc., 134, 1315-1326, 2008

Steppeler, J., Doms, G., Schättler, U., Bitzer, H., Gassmann, A., Damrath, U., and Gregoric, G.: Meso-gamma scale forecasts using the nonhydrostatic model LM, Meteorol. Atmos. Phys., 82, 75-96, 2003.

Stevens, B. and Feingold, G.: Untangling aerosol effects on clouds and precipitation in a buffered system, Nature, 461, 607-613, 2009.

Tao, W.-K., Chern, J.-D., Atlas, R., Randall, D., Khairoutdinov, M., Li, J.-L., Waliser, D. E., Hou, A., Lin, X., Peters-Lidard, C., Lau, W., Jiang, J., and Simpson, J.: A multiscale modeling system: developments, applications, and critical issues, B. Am. Meteorol. Soc., 90, 515-534, doi:10.1175/2008BAMS2542.1, 2009.

Teller, A. and Levin, Z.: The effects of aerosols on precipitation and dimensions of subtropical clouds: a sensitivity study using a numerical cloud model, Atmos. Chem. Phys., 6, 67-80, doi:10.5194/acp-6-67-2006, 2006.

Tiedtke, M.: A comprehensive mass flux scheme for cumulus parameterization in large-scale models, Mon. Weather Rev., 117, 1779-1800, 1983

van den Heever, S. C., Stephens, G. L., and Wood, N. B.: Aerosol indirect effects on tropical convection characteristics under conditions of radiative convective equilibrium, J. Atmos. Sci., 68 , 699-718, doi:10.1175/2010JAS3603.1, 2011.

van den Heever, S. C., Carrio, G. G., Cotton, W. R., DeMott, P. J., and Prenni, A. J.: Impacts of nucleating aerosol on Florida storms. Part I: Mesoscale simulations, J. Atmos. Sci., 63, 1752- 
1775, 2006.

Vogel, B., Vogel, H., Baeumer, D., Bangert, M., Lundgren, K., Rinke, R., and Stanelle, T.: The comprehensive model system COSMO-ART - Radiative impact of aerosol on the state of the atmosphere on the regional scale, Atmos. Chem. Phys., 9, 86618680, doi:10.5194/acp-9-8661-2009, 2009.

Wang, M., Ghan, S., Easter, R., Ovchinnikov, M., Liu, X., Kassianov, E., Qian, Y., Gustafson, Jr., W. I., Larson, V. E., Schanen, D. P., Khairoutdinov, M., and Morrison, H.: The multiscale aerosol-climate model PNNL-MMF: model description and evaluation, Geosci. Model Dev., 4, 137-168, doi:10.5194/gmd4-137-2011, 2011.
Wicker, L. J. and Skamarock, W. C.: Time-splitting methods for elastic models using forward time schemes, Mon. Weather Rev., 130, 2088-2097, 2002.

Xue, H., Feingold, G., and Stevens, B.: Aerosol effects on clouds, precipitation, and the organization of shallow cumulus convection, J. Atmos. Sci., 65, 392-406, 2008.

Zubler, E. M., Folini, D., Lohmann, U., Mühlbauer, A., PousseNottelmann, S., Schär, C., and Wild, M.: Implementation and evaluation of aerosol and cloud microphysics in a regional climate model, J. Geophys. Res., 116, D02211, doi: 10.1029/2010JD014572, 2011. 